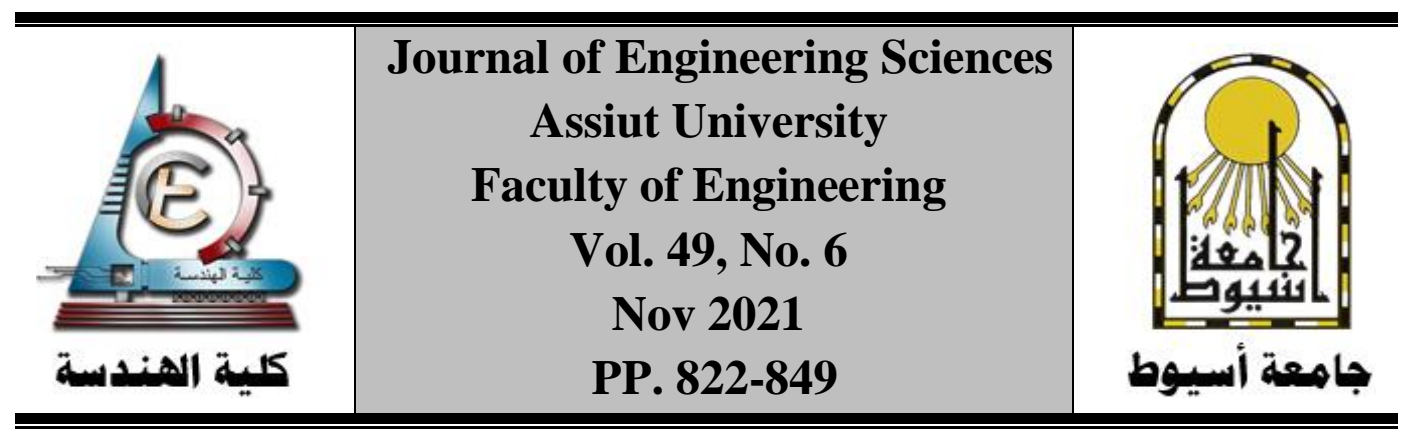

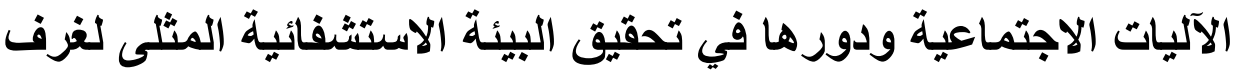

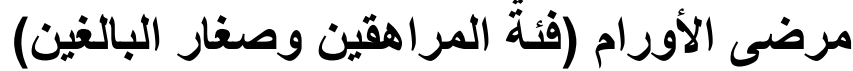 \\ هاجر حمدي محمد'، خالد محمد أحمد الليثيّ، نوبي محمد حسنَّ
}

$$
\begin{aligned}
& 1 \text { باحث ماجستبر_قسم العمارة- جامعة أسبوط } \\
& 2 \text { مدرس-قسم العدارة- جامعة أسبيوط } \\
& 3 \text { أستاذ_قسم العمارة- جامعة أسبيوط }
\end{aligned}
$$

Received 11 June 2021; Revised 19 September 2021; Accepted 27 September 2021

ملخص البحث:

تناقش الورقة البحثية أهمية الآليات الاجتماعية كأحد العناصر الأساسية لتحقيق منظومة البيئة الاستشفائية

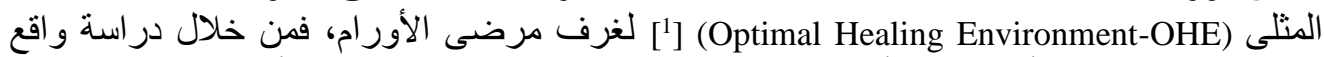

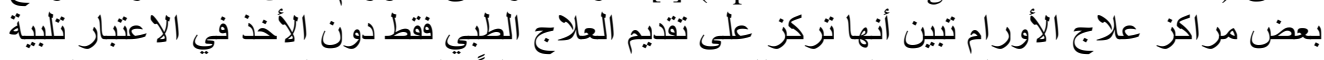

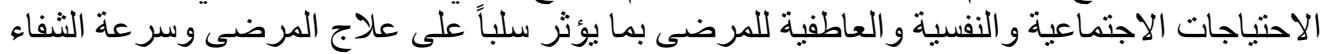

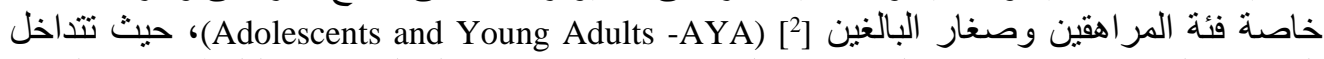

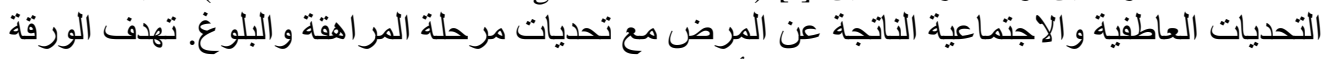

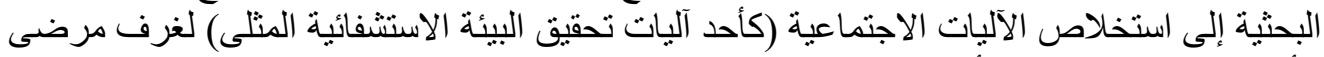

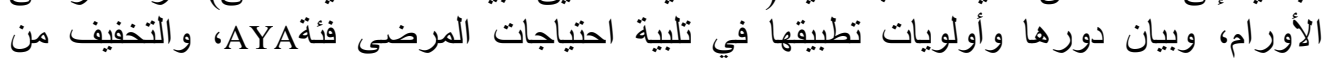

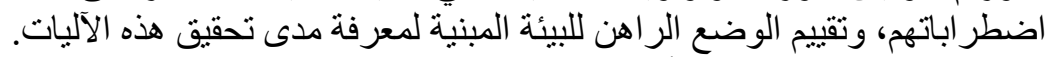

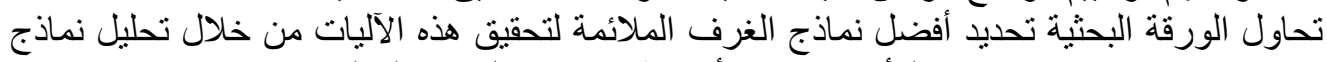

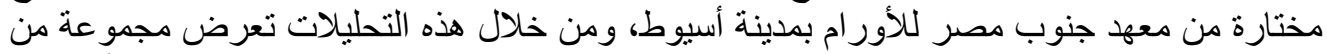

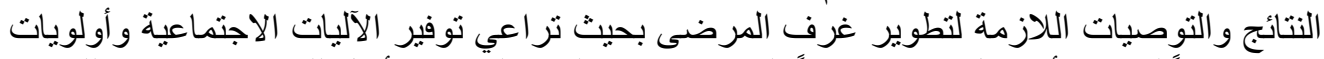

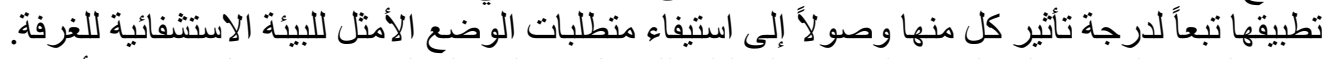

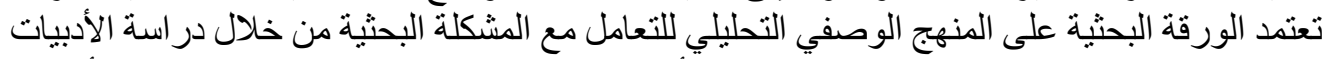

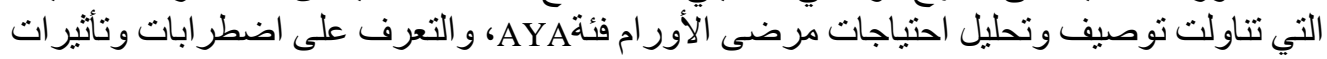

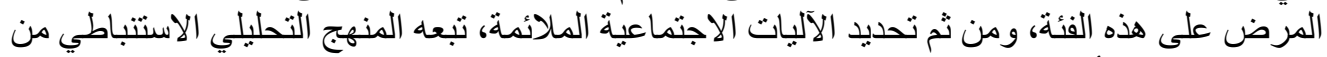

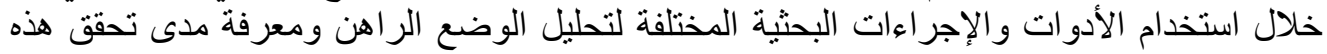

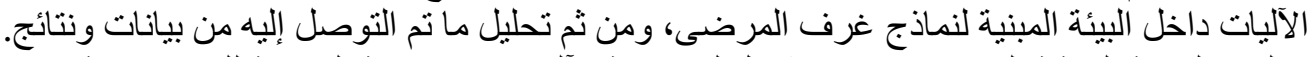

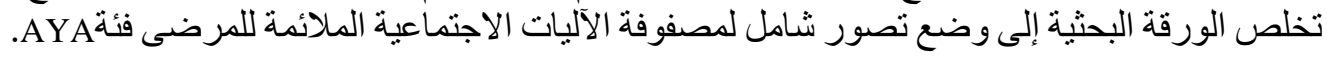

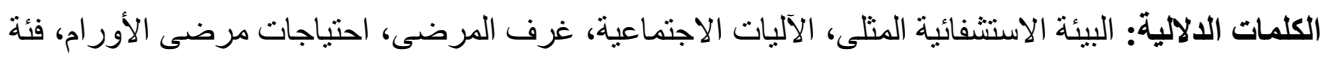
المر اهقين وصغار البالغين.

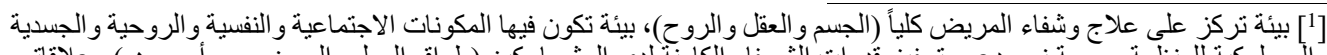

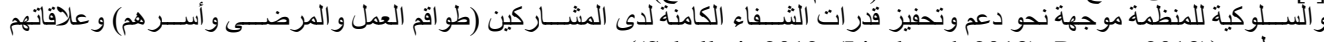

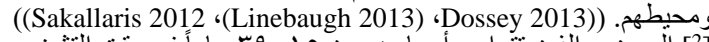

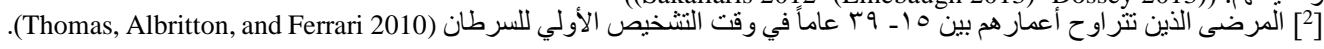


تمثل احتياجات الدعم النفسي و الاجتماعي لفئة AYA من مرضى الأو الأورام عنصر اً مهماً لهذه الفئة

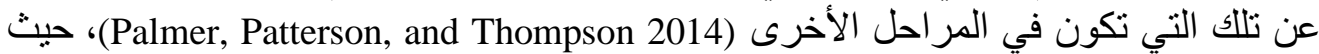

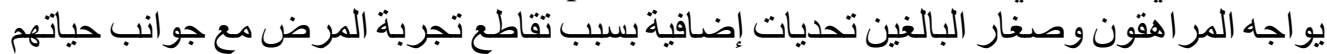

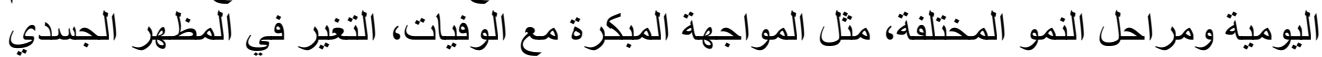

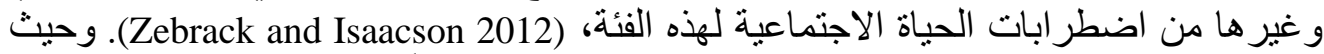

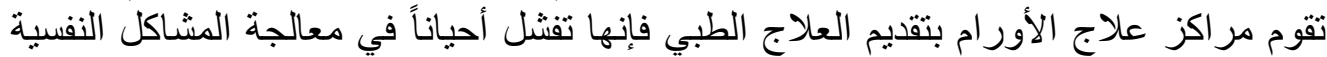

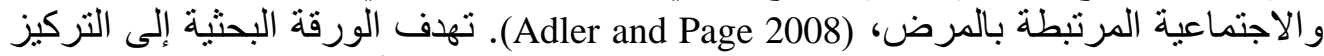

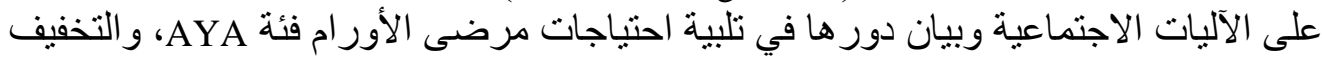

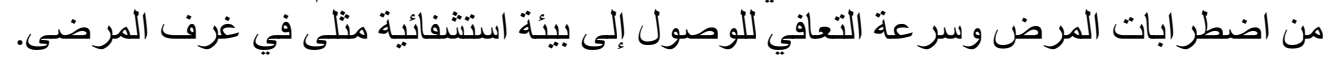

1 - 1 المشكلة البحثية

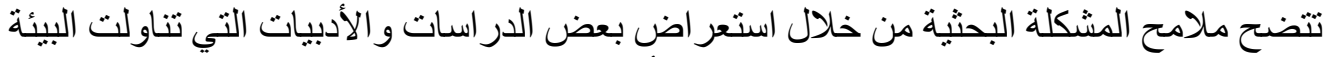

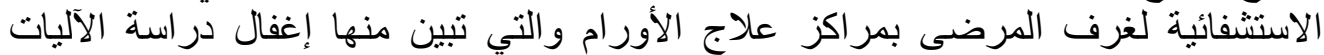

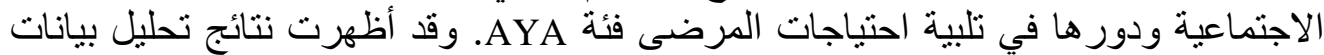

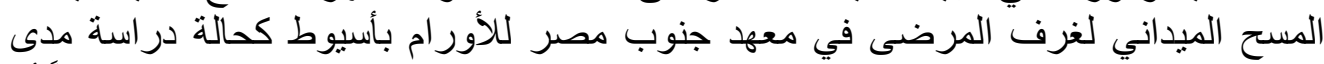

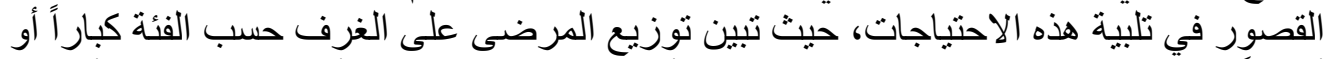

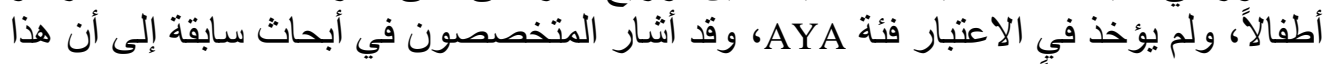

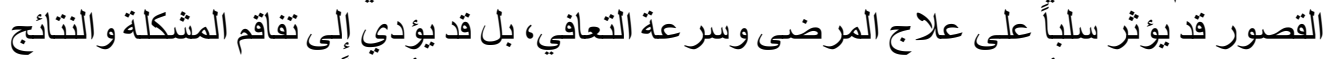

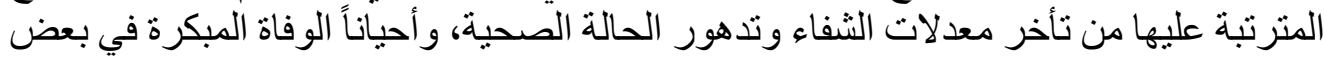

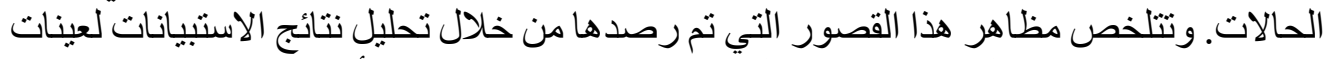

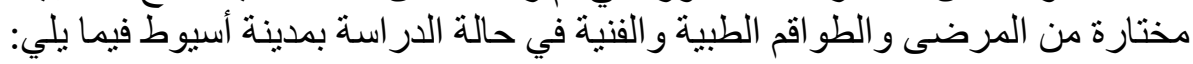

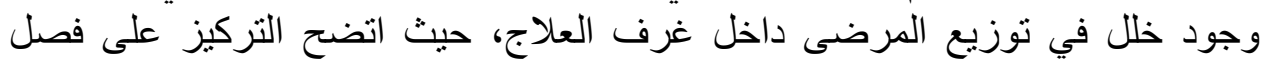

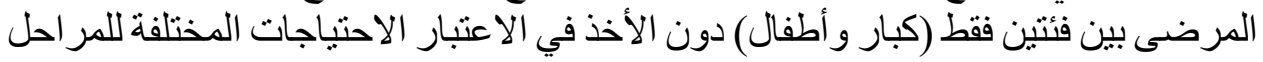
العمرية لفئة المر اهقين وصنغار البالغين.

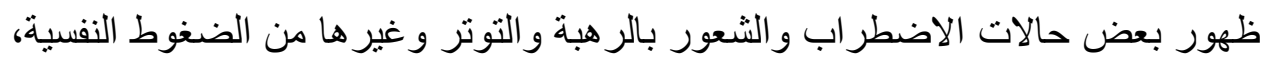

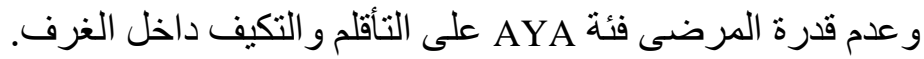

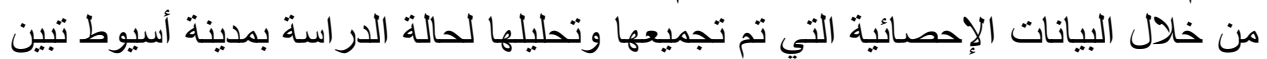

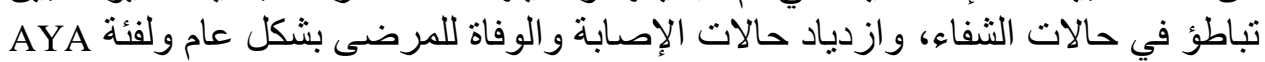

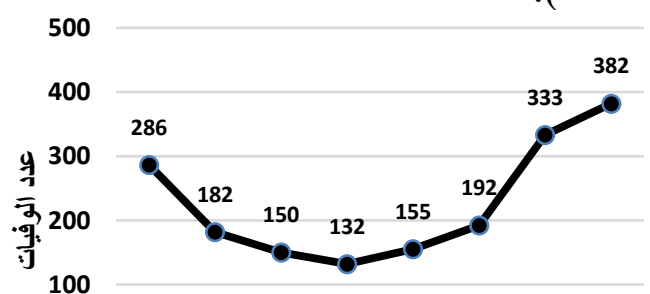

0

20102011201220132014201520162017 شكل (r): عدد الوفيات لمرضى مركز الأورام بأسيوط

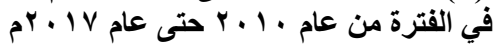

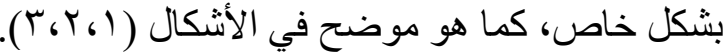

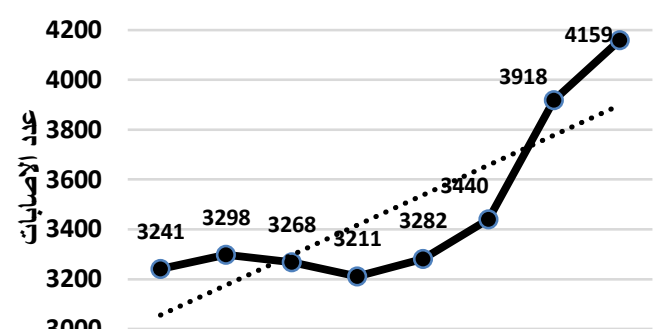

20102011201220132014201520162017 شكل (1): عدد حالات الإصابة لمرضى مركز الأورام

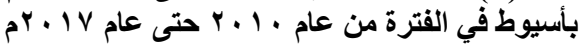




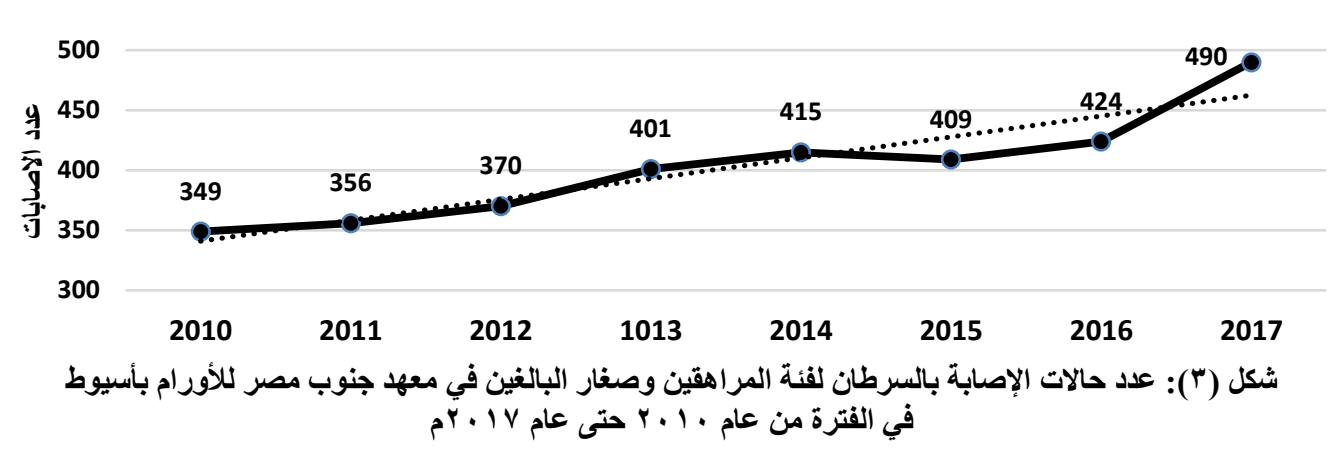

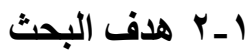

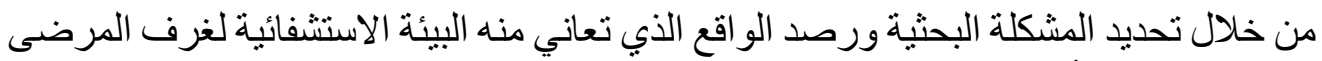

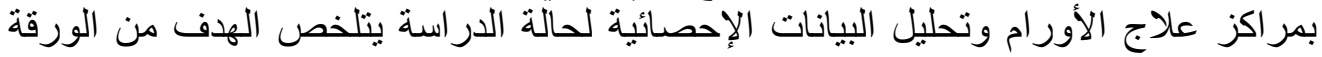

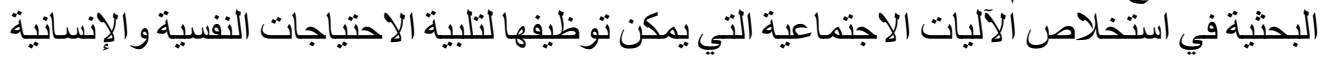

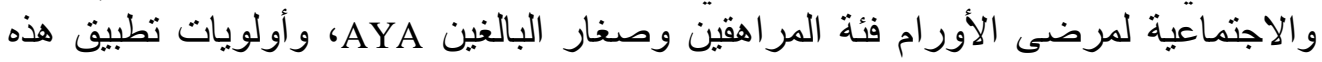

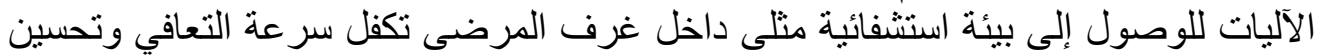

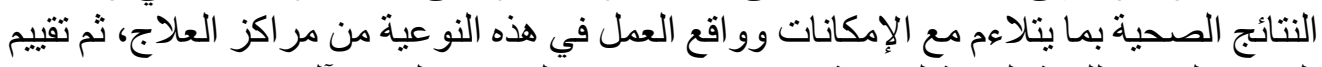
الوضع الر الهن للبيئة المبنية لمعرفة مدى تحقيق غرف الانف المرضى لهذه لهذه الآليات.

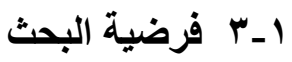

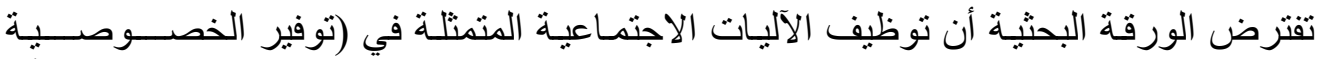

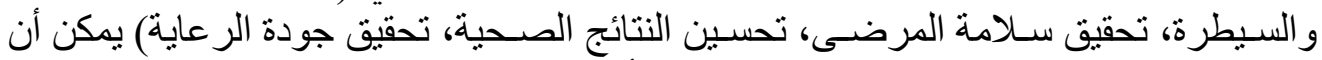

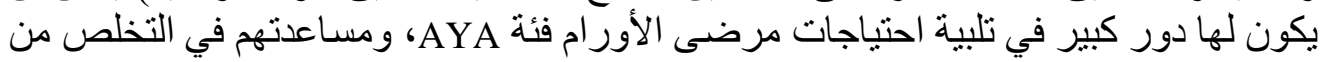

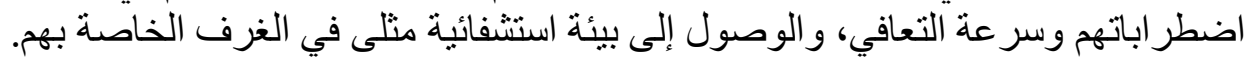

-

تعتمد الورقة البحثية على مجمو عة من الخطو البه اتلى المنهجية للتعامل مع المشكلة البحثية وتحقيق

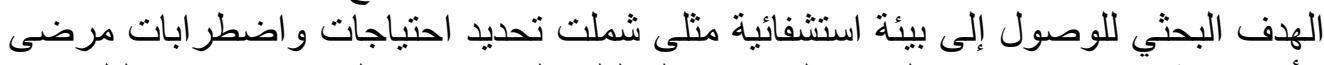

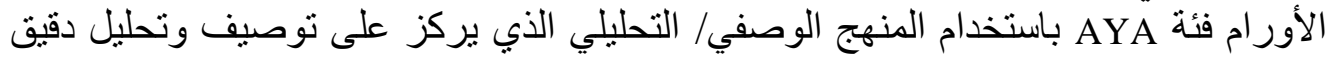

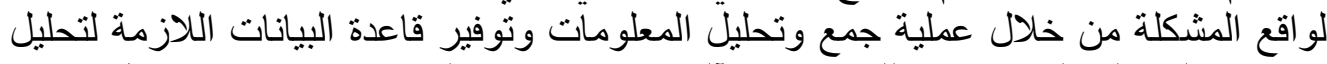

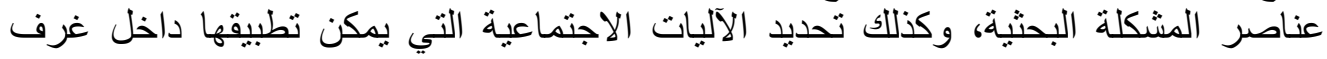

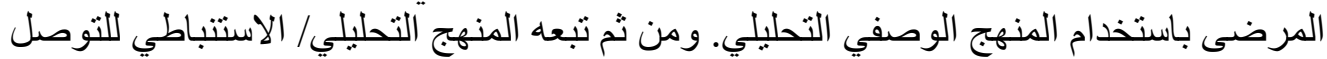

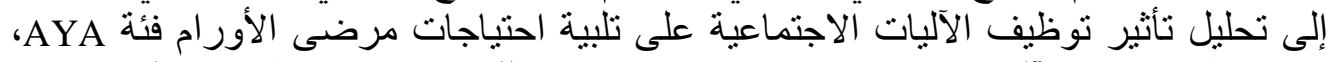

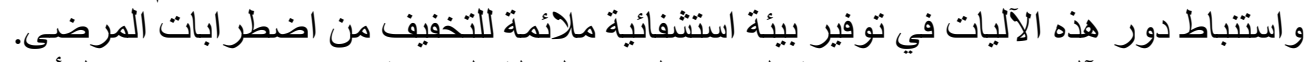

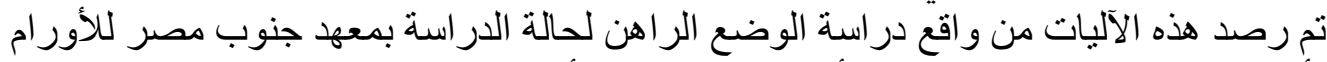

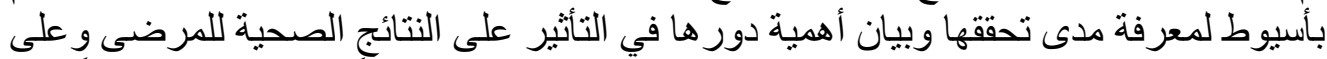

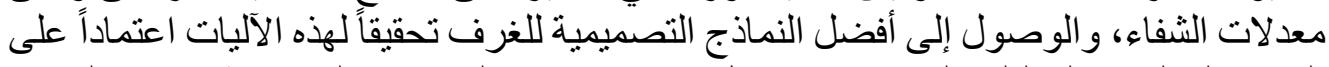

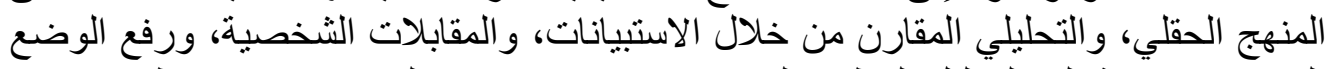

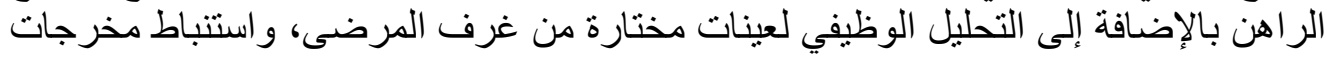

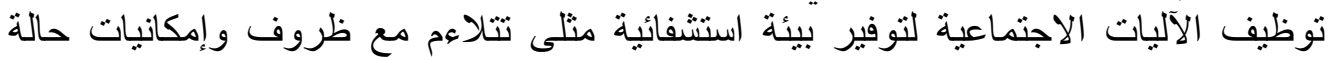

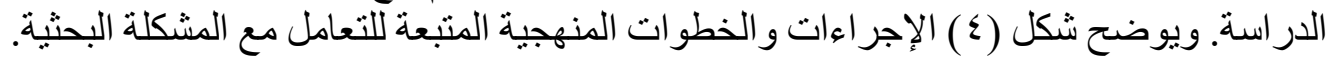




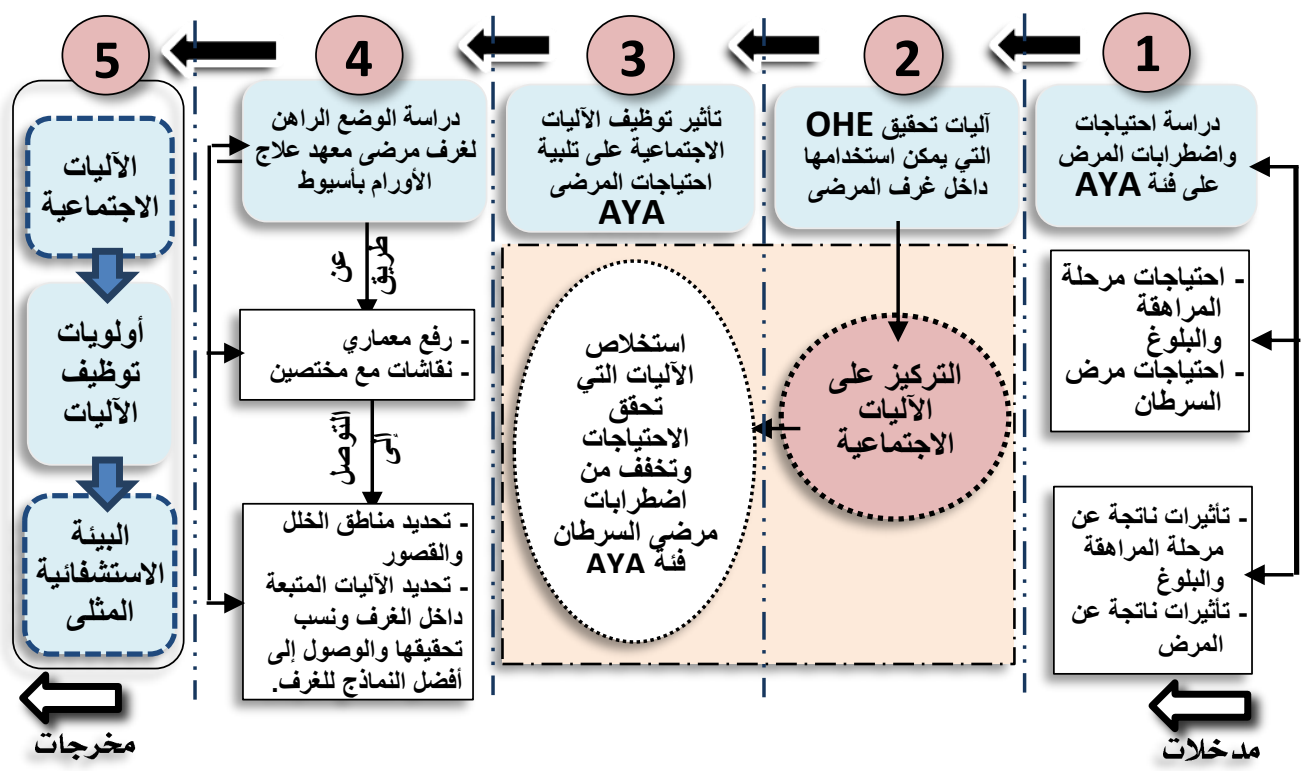

شكل (؛ ) ): الخطوات المنهجية المتبعة للتعامل مع المثكلة البحثية

r باصر منظومة البيئة الاستثفائية لمريض الأورام

بيئة الاستشفاء هي البيئة التي تركز حول المريض مع مع معرفة الاحتياجات و العمل على تلبيتها

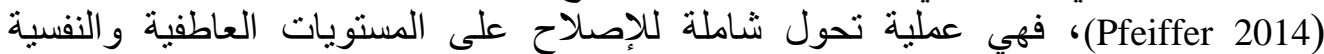

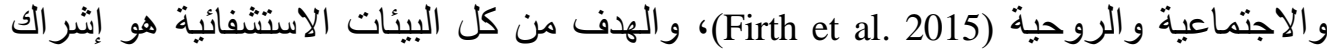

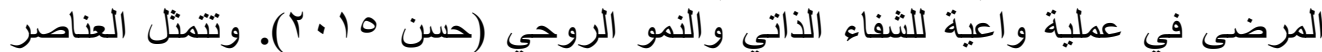

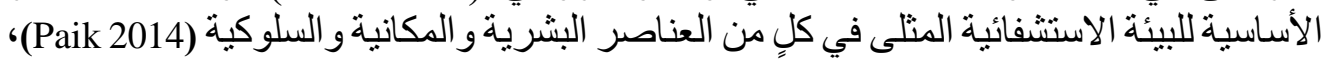

كما هو موضح في شكل (0).
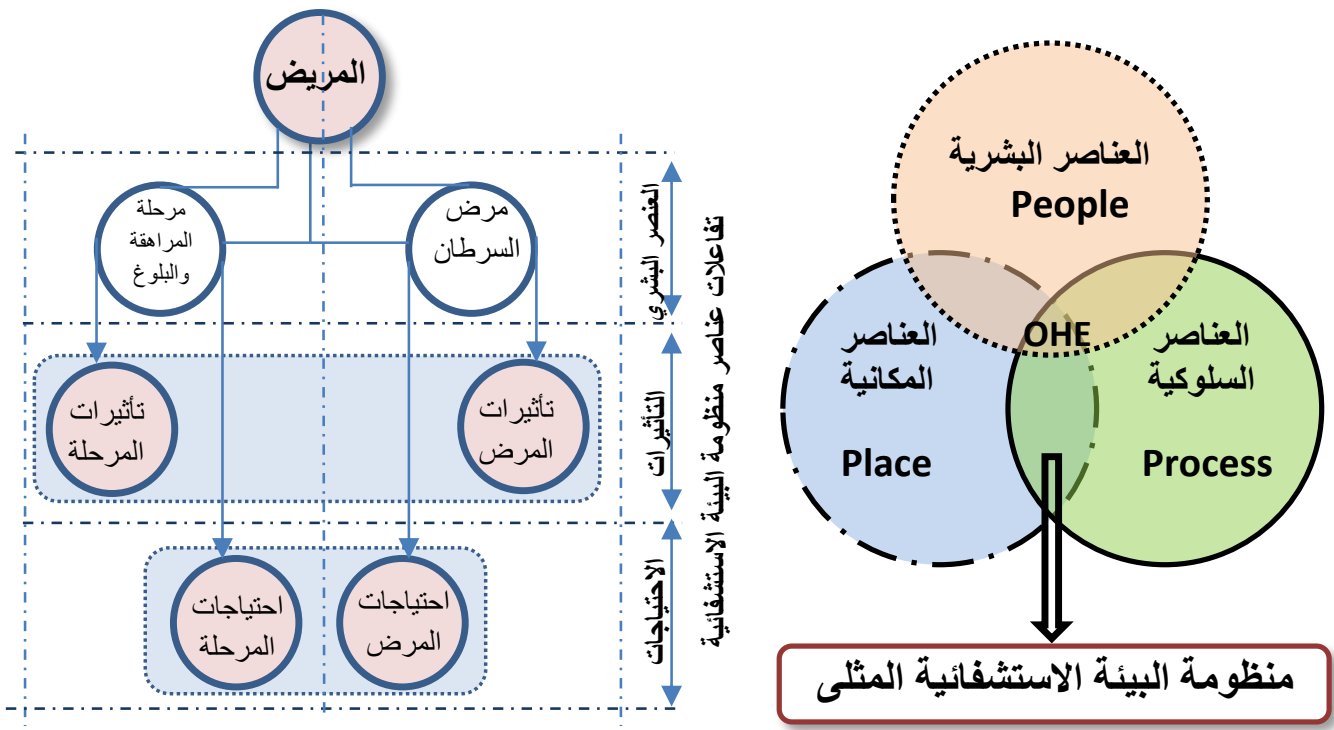

شكل (•): عناصر منظومة البيئة الاستثفائية المثلى 
بالإضافة إلى الاحتياجات المكانية فإن العناصر الأساسية لبناء منظومة متكاملة للبيئة الاستثفائية

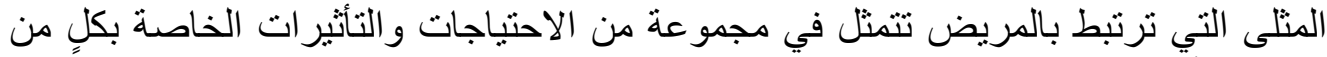
مرض الأورام ذاته و المرحلة العمرية للمريض. فتئ.

Y - ا تعريف فئة المراهقين وصغار البالغين AYA ظهرت أوجه تناقض واختلاف كثيرة في تحديد نطاق العمر لفئة AYA

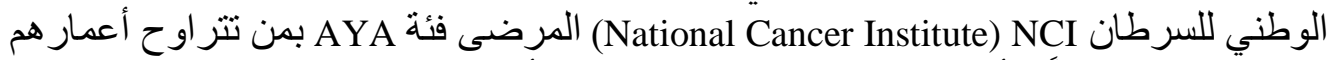

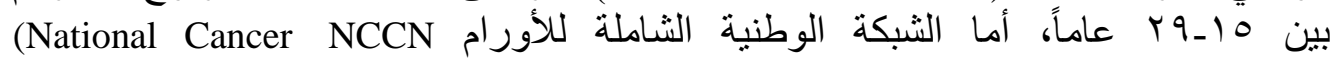

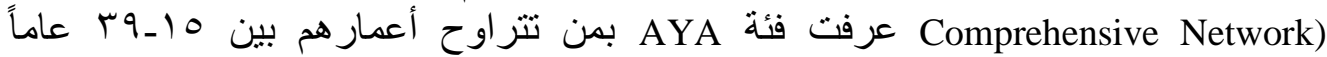
(Thomas, Albritton, and Ferrari 2010)

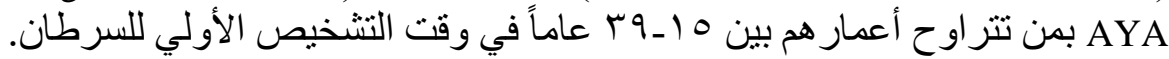

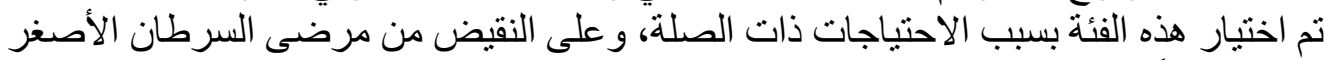

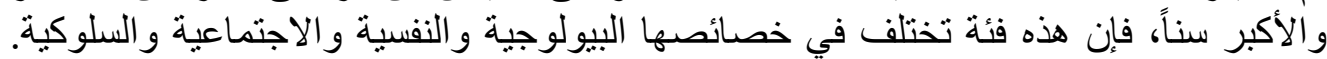

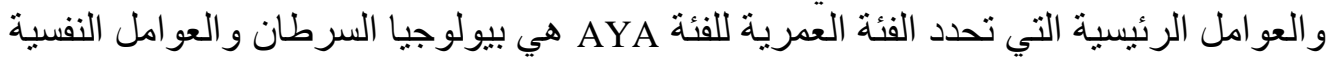

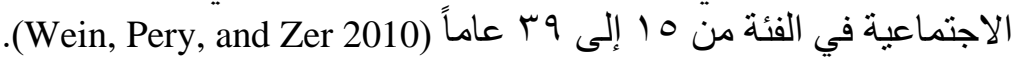

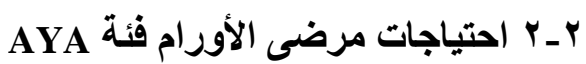

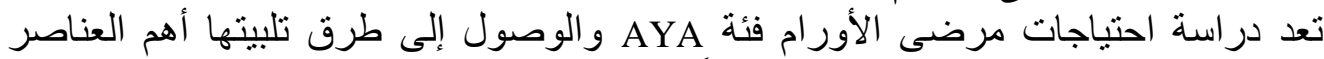

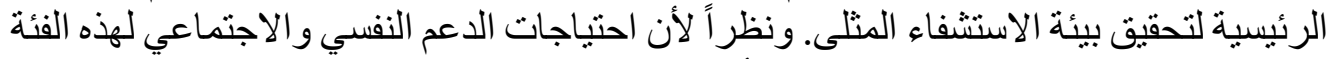
مختلفة عن تللك التي تكون في المر احل الأخرى، (Palmer, Patterson, and Thompson 2014)

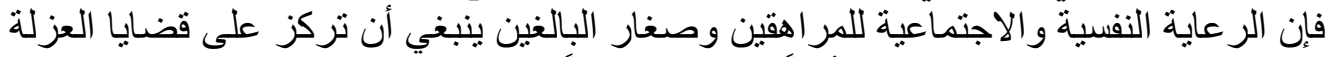

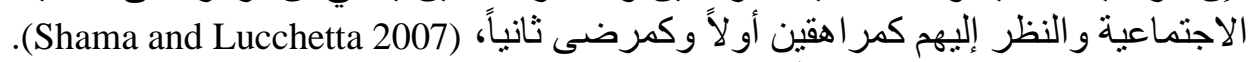

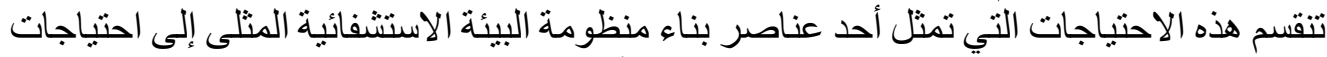

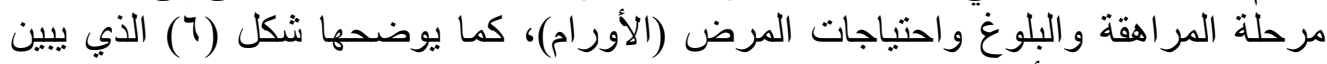

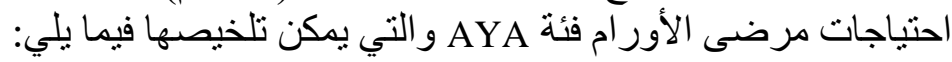

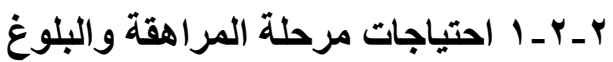

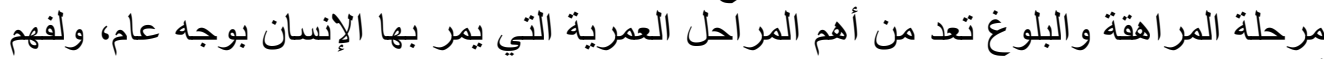

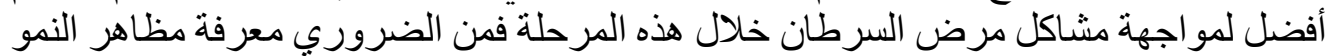

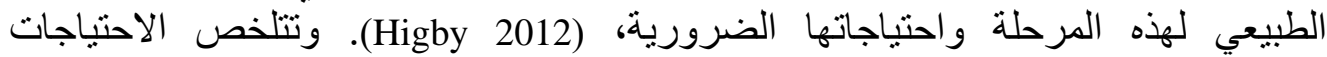
والمتطلبات و التحديات المتعلقة بفئة AYA في تحقيق الهوية الثخصية والذية والذات، والحرية

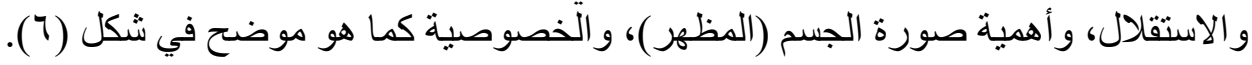

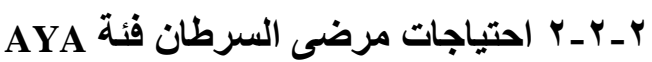

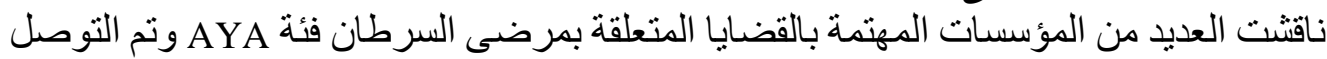

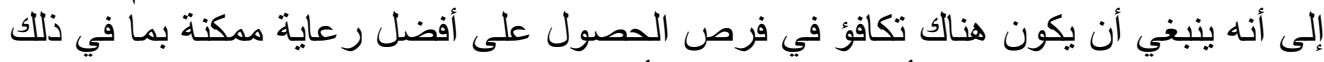

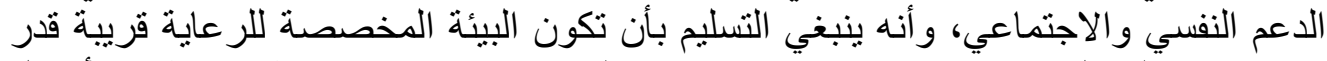

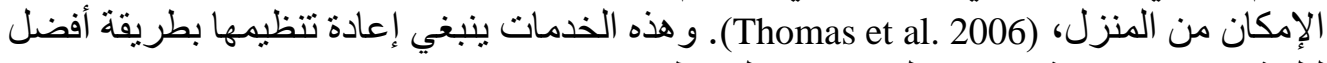

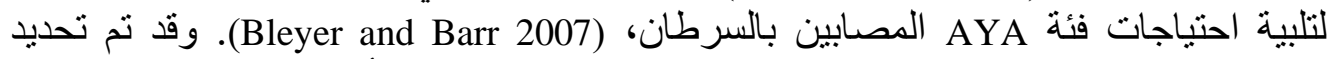

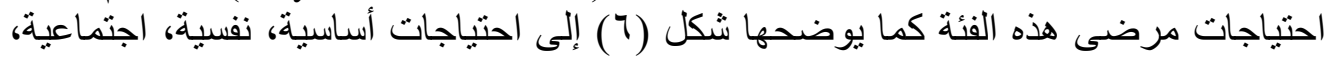




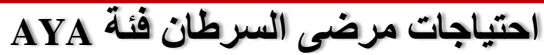

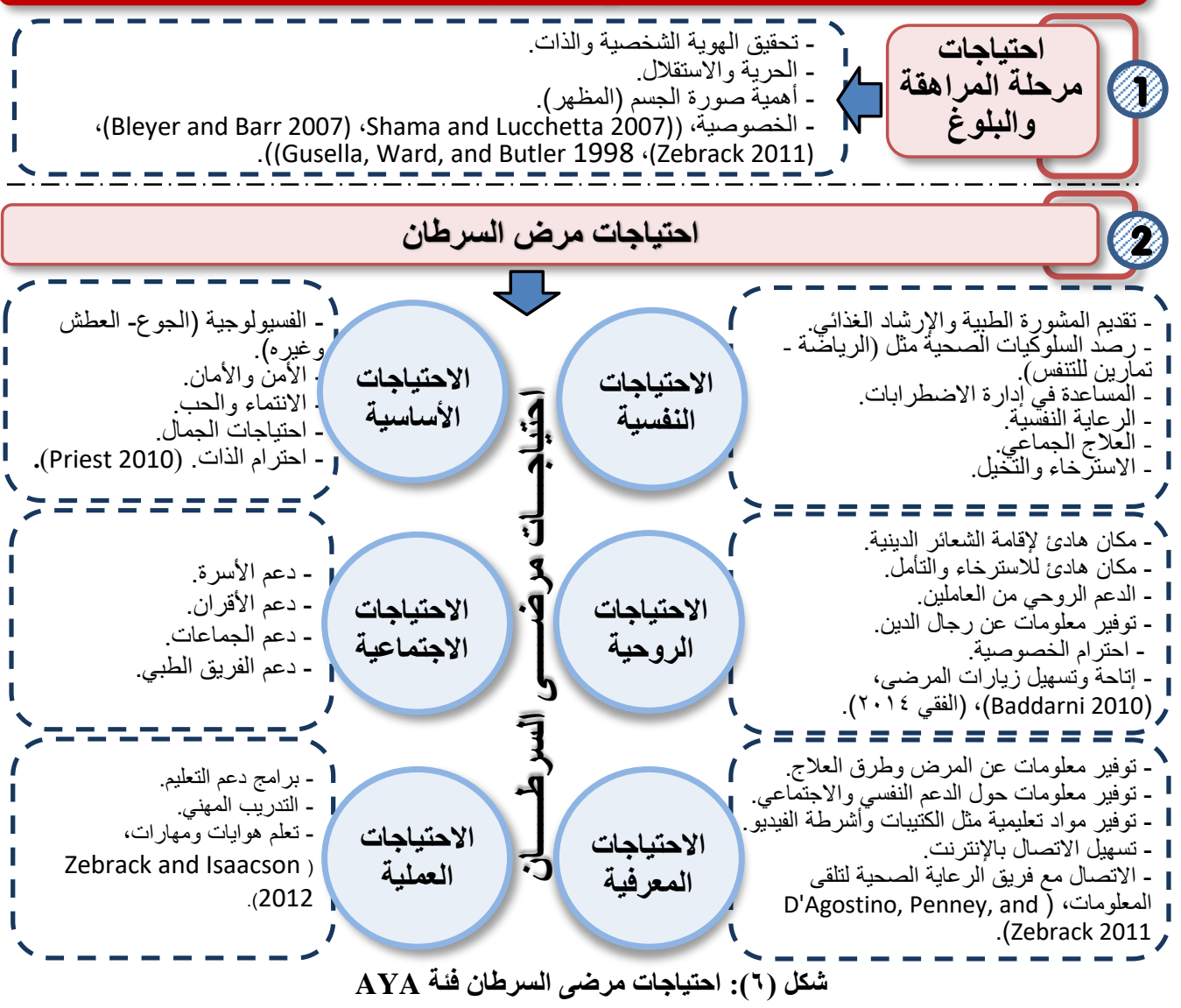

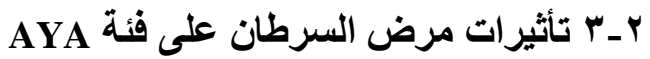

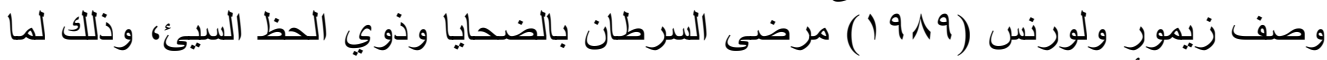

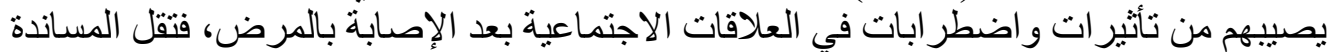

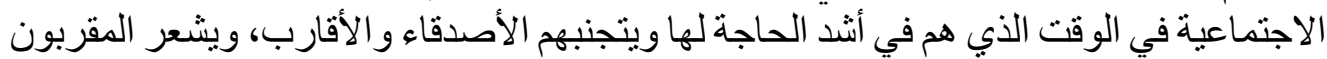

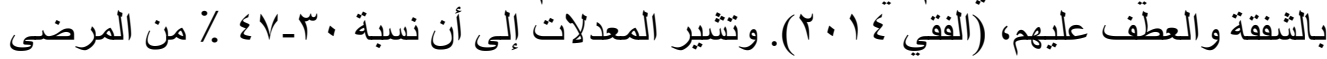
بالسرطان لايهم معاناه نفسية في مختلف مراحل المرض، ( A

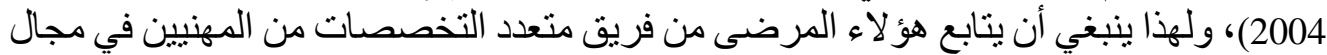

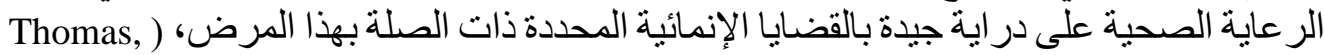

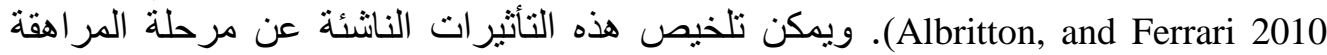
و البلوغ و التأثير ات الناشئة عن مرض السرطان كما يوضحها شكل (V) فيما يلي: لئي:

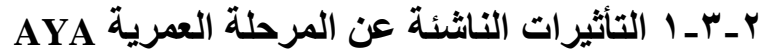

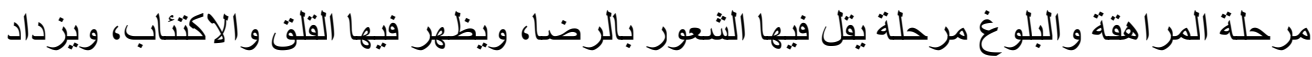

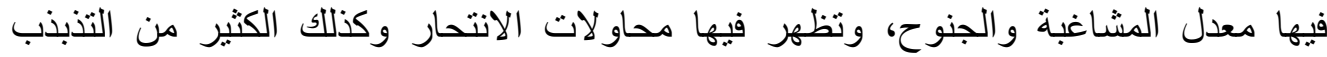

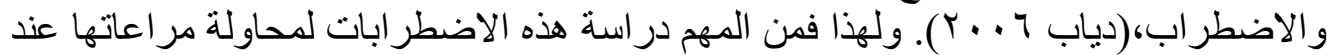

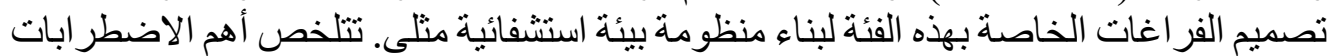




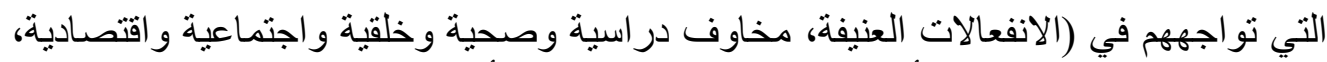

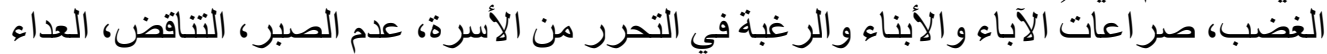

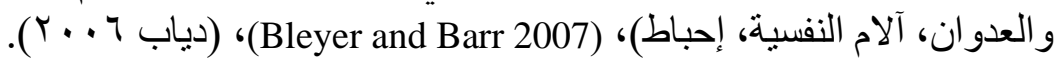

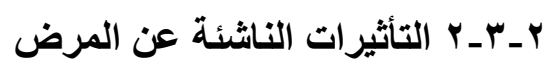

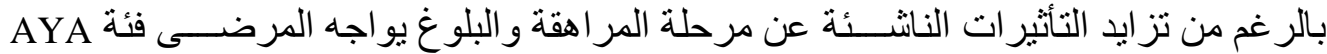

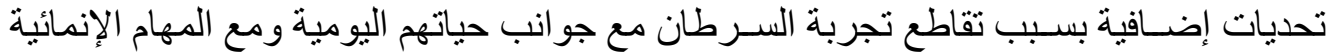

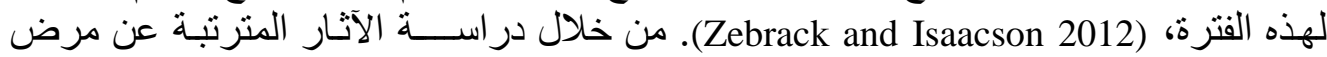

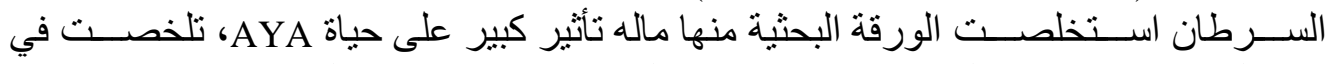
(اضطر ابات نفسية، اضطر ابات اجتماعية، اضطر ابات القتصادية، اضطر ابات الثية روحية).

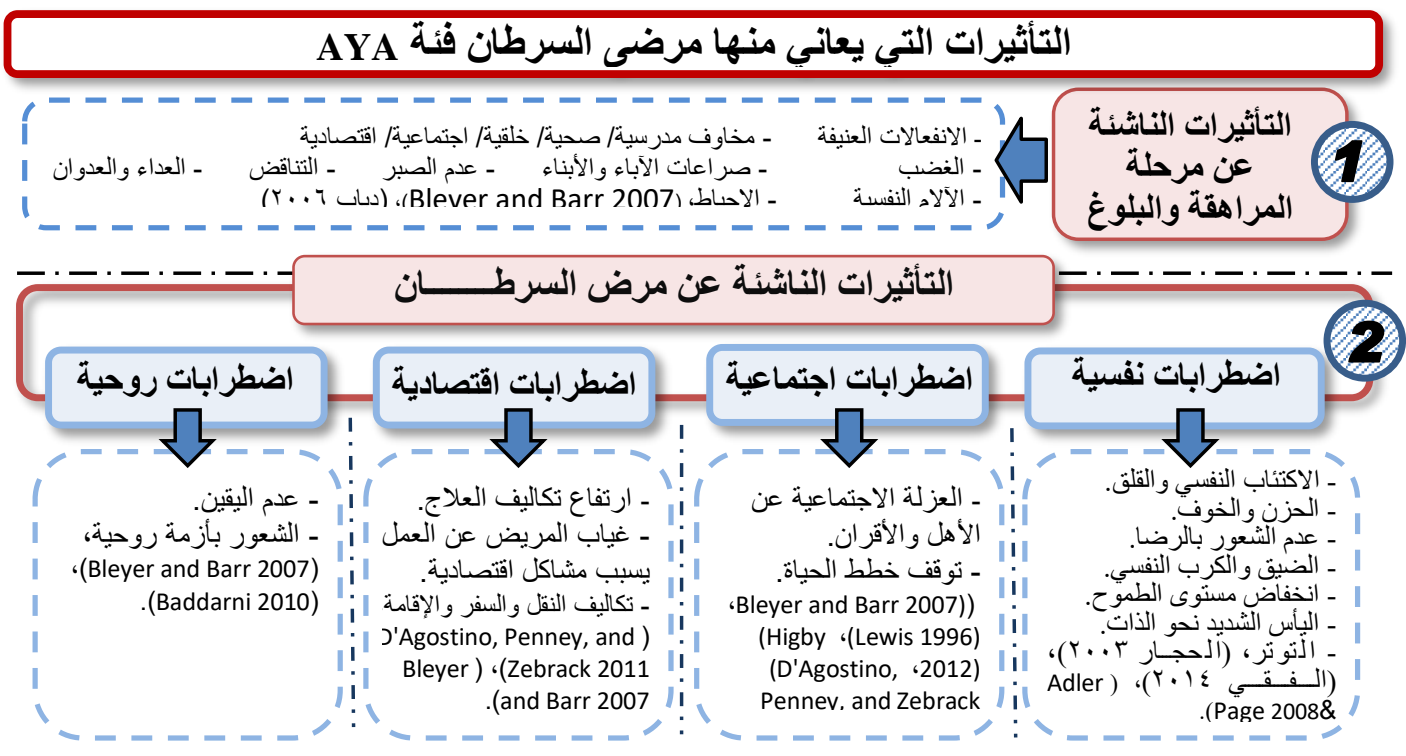

AYA (V) التأثيرات والاضطرابات التي يعاني منها مرضى السرطان فئة

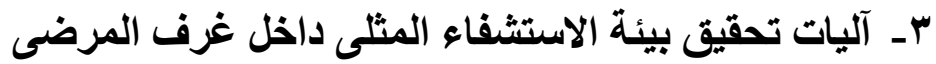

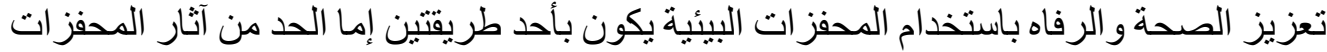

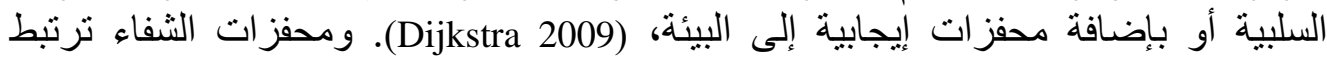

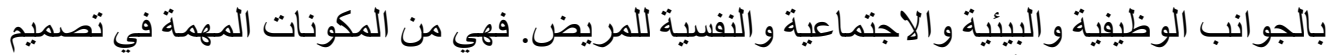

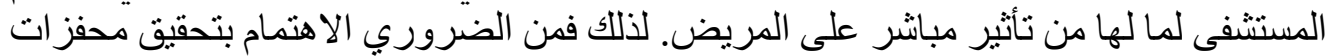

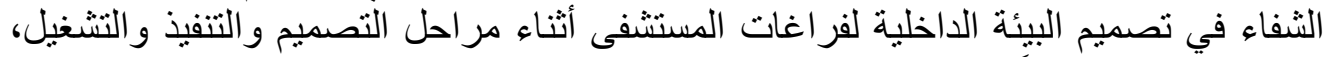

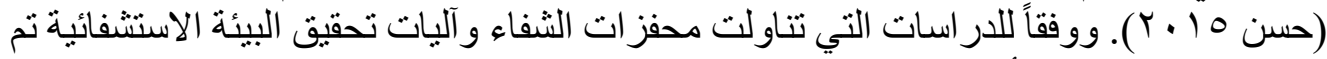

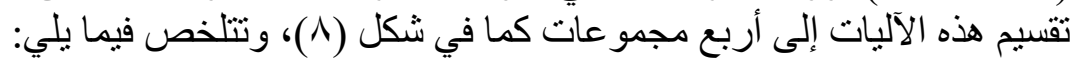

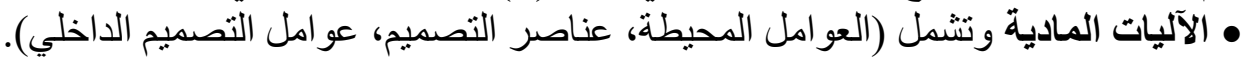

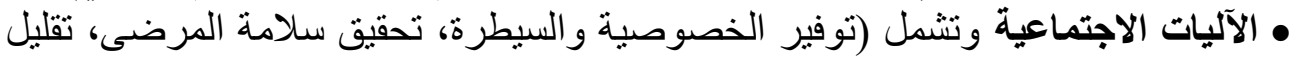

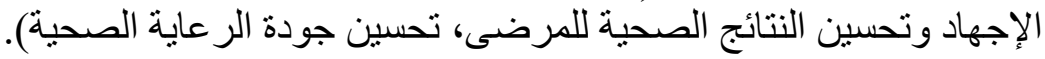
• الآليات العلاجية وتتشل (آليات علاجية مادية، آليات علاجية الإنية نفسية). • الآليات التقتية وتثمل (تجارب فيليبس، الواقع الافتراضية الياتي، الفيديو و الرسوم المتحركة). 


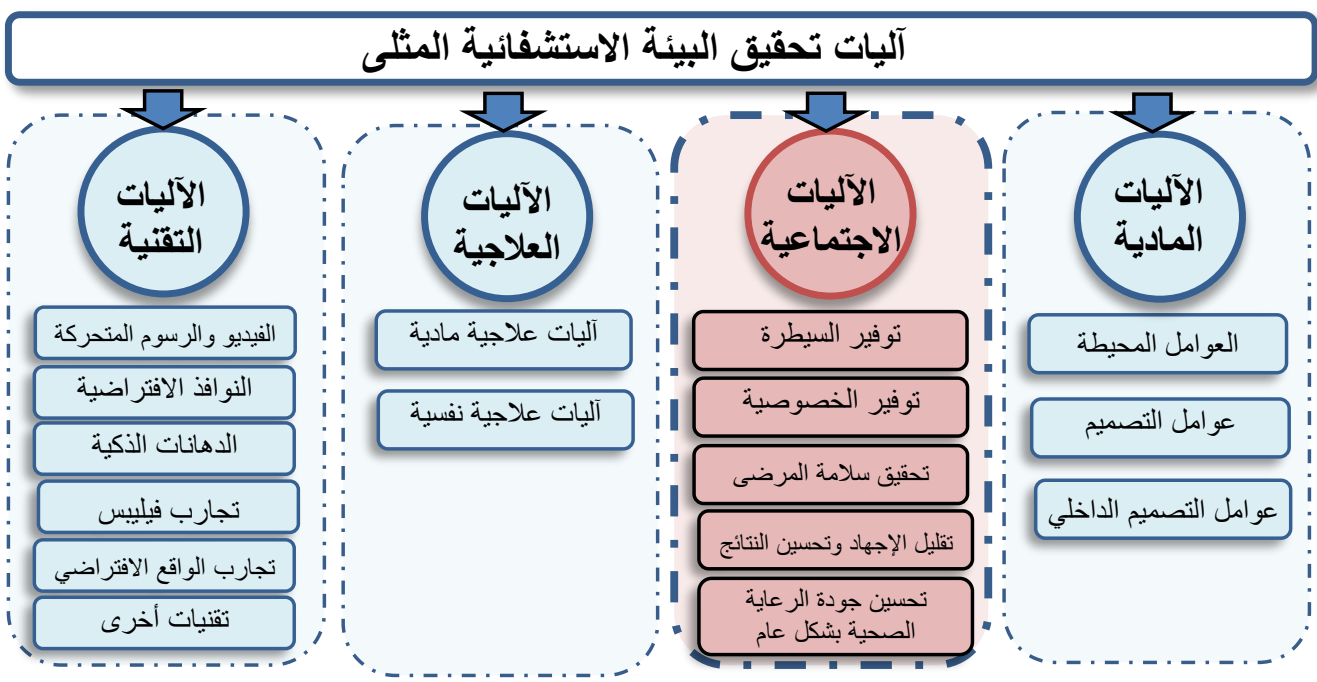

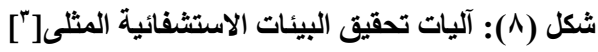

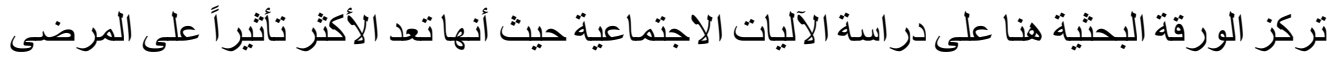

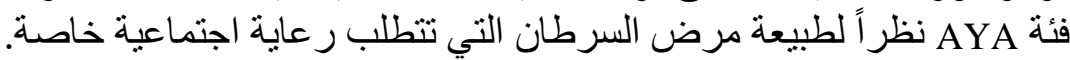

بـ ـ الآليات الاجتماعية ودورها في تحقيق البيئة الاستشفائية المثلى الإئ

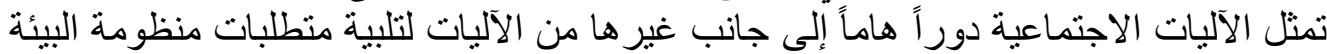

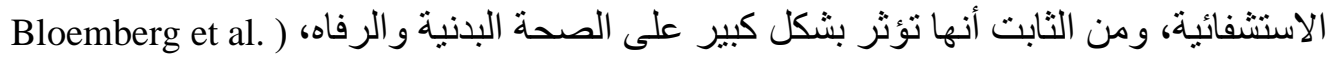

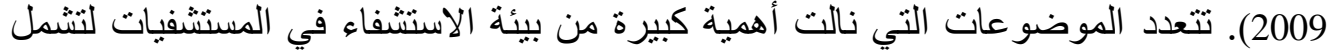

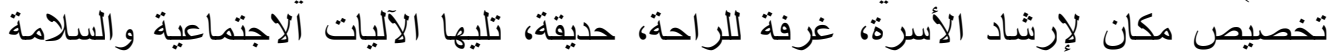

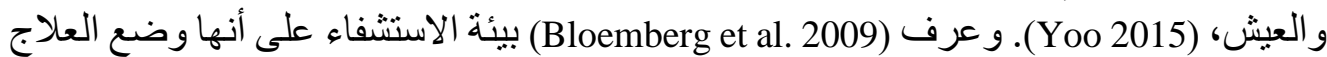

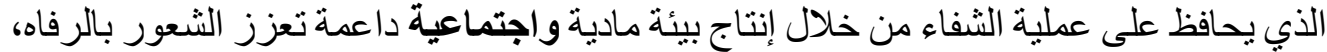

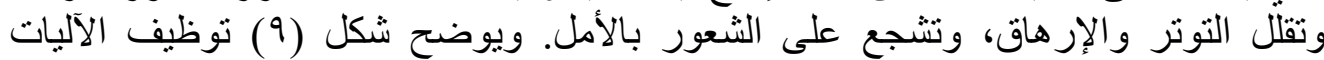

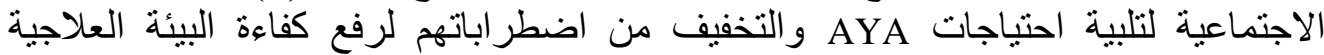

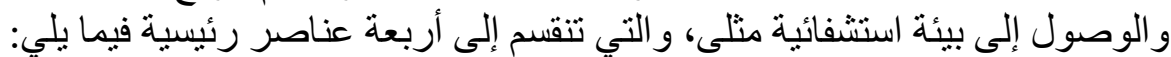
• توفير الخصوصية والسيطرة عن طريق (الاستقلاليةـ القدرة على التحكم في مكونات البئية البئة

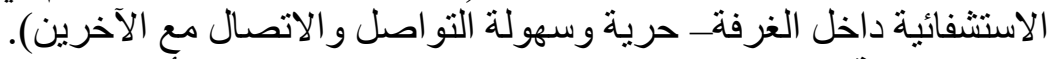

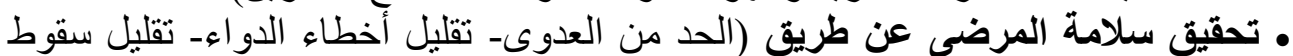

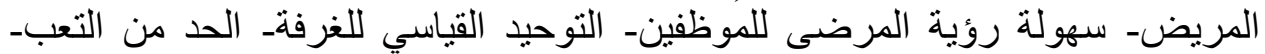

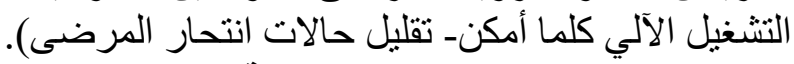

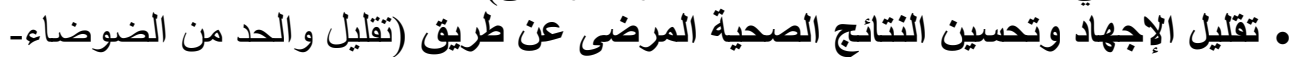

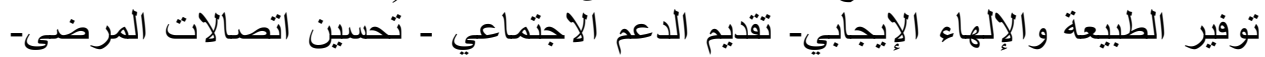

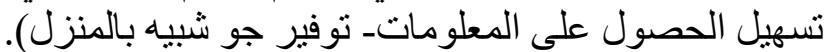

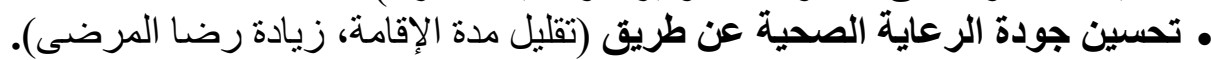




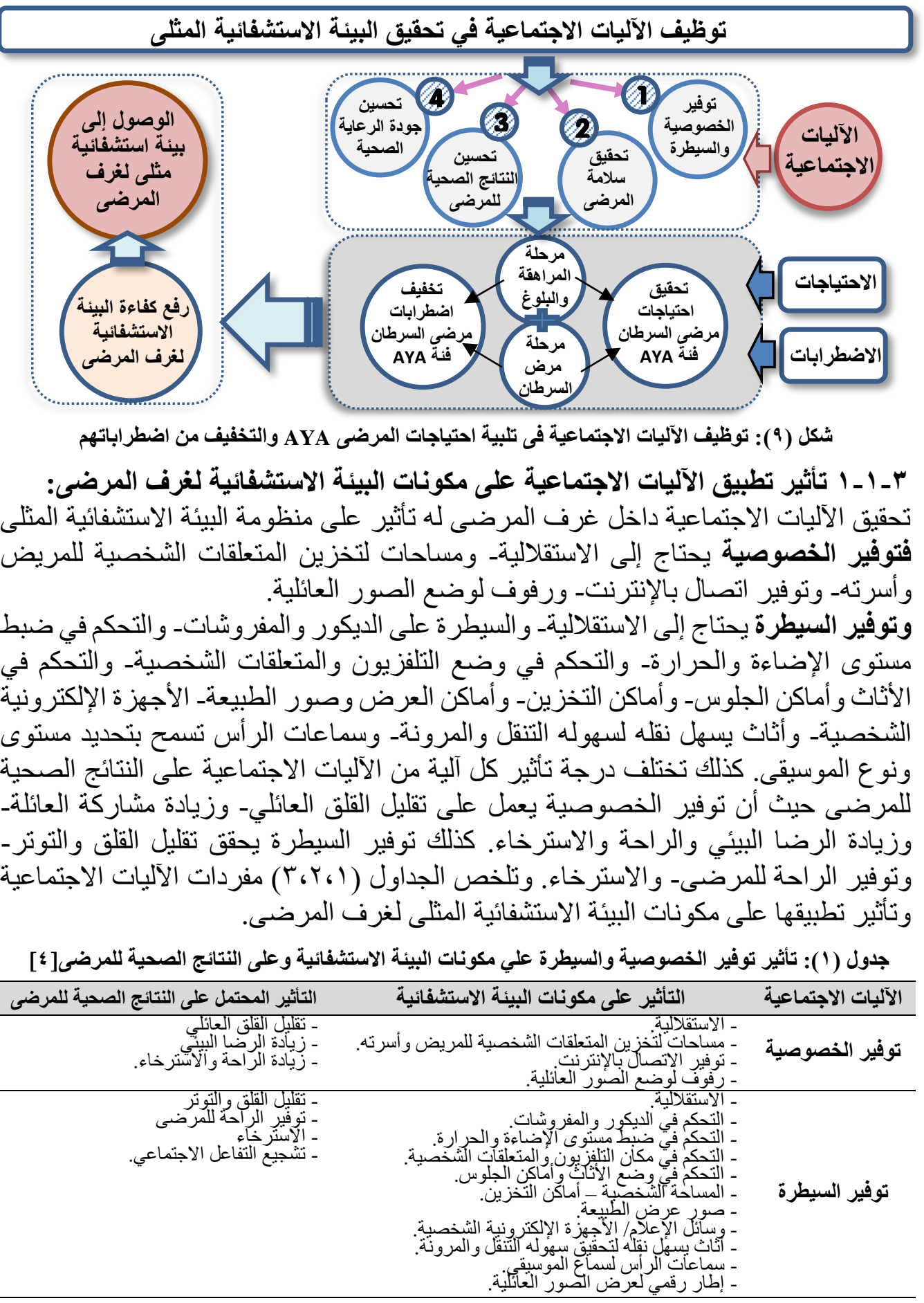

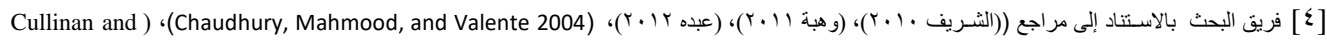
، (Miller 2010) ، (Phillips 2012) .(Zimring, Joseph, and Choudhary 2004) ، (Oi-Zhen, Weng-Wai, and Yu-Tian 2015) ، (Wolf 2010 (Reiling, Hughes, and Murphy 2008).(Henriksen et al. 2007) ، (Alfonsi, Capolongo, and Buffoli 2014) .(Bloemberg et al. 2009) 
ATI

هاجر حدي، خالد الليثي، نوبي حسن، الآليات الاجتماعية ودورها في تحقيق البيئة الاستشفائية الدثلى لغرف مرضى الأورام

جدول (Y): تأثير تحقيق سلامة المرضى على مكونات البيئة الاستثفائية وعلى النتائج الصحية للمرضى[ ؛ ]

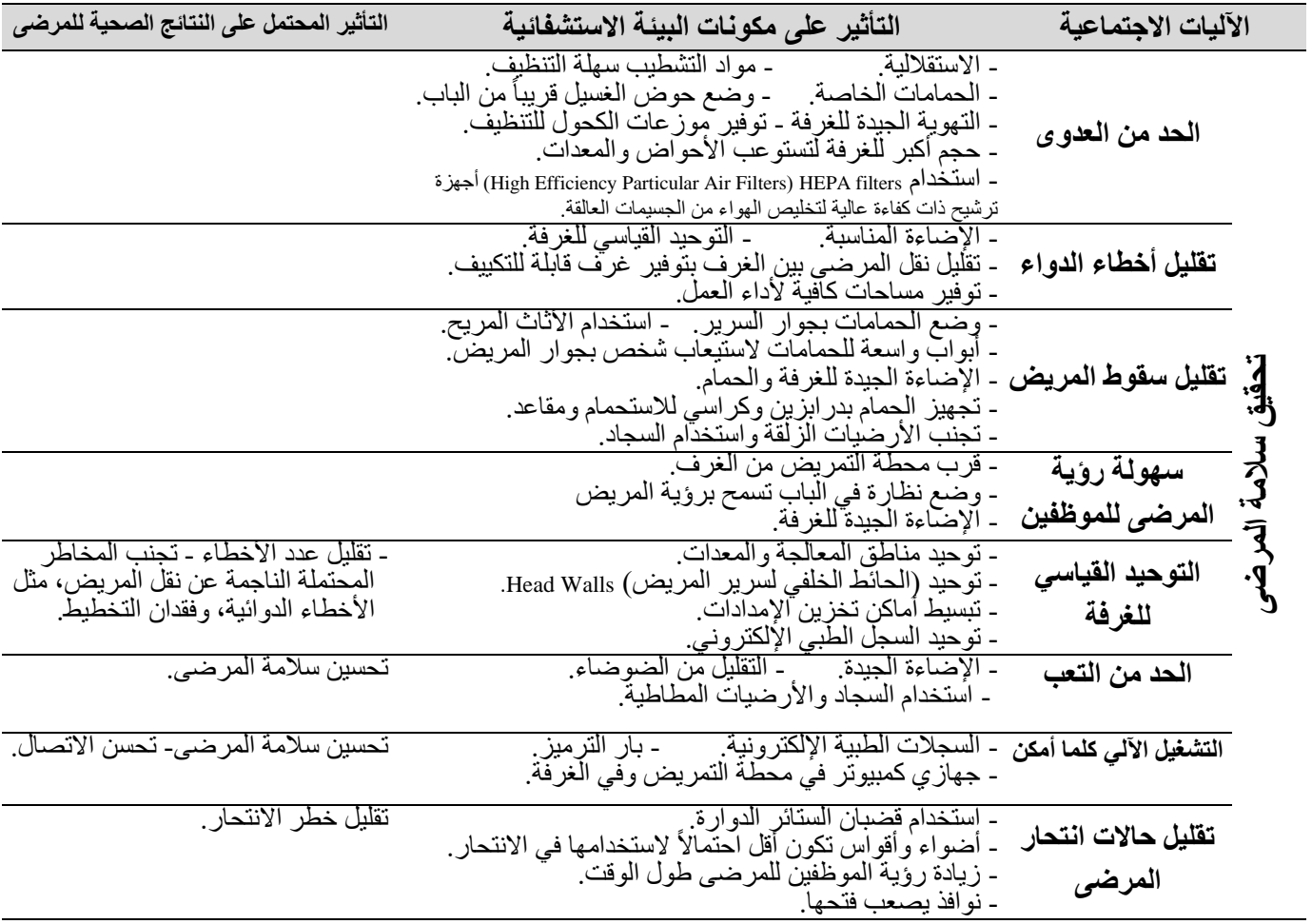

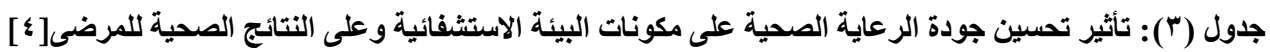

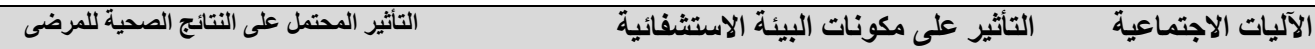

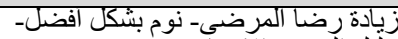

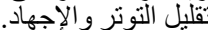

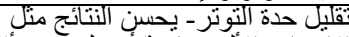

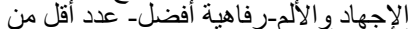

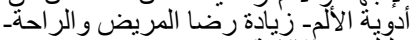
تقليل مدة الإقامة.

ضغط أقل- صحة افضل - تحسين نتائج

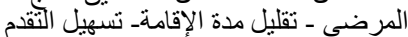
السريريـ تقليل القلق و الإجهاد و الاكتئاب- تلفئ.

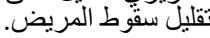

الحد من القلق - تحسين الرعاية في المنزل

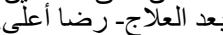

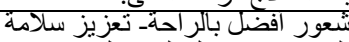
المرضى- تسهيل التو اصل.

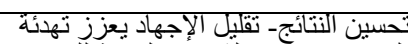
المرضى- تعزز الثعور بالر احة للمريض. لئ.

البيئة اكثر راحة_ تخفف التوتر - تحسين

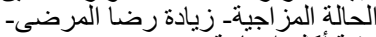

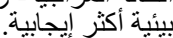

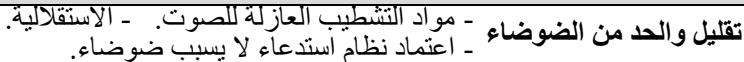

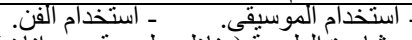
ـ مشاهدة الطبيعة (مناظر طبيعية- حيو انات).

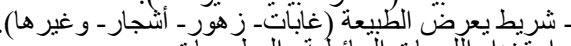

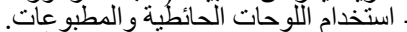

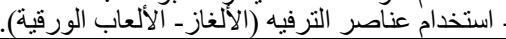

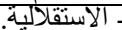

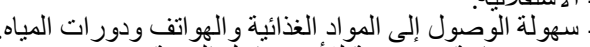

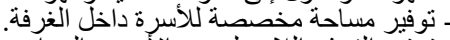

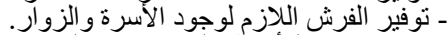

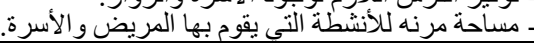
الطيجة

"ُُ3.

تحسين اتصالات المرضى - الاستقلالية باستخدام الغرف المفردة.

تسهيل الحصول على

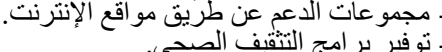

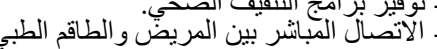

توليل والجد من الضوضياء
湿

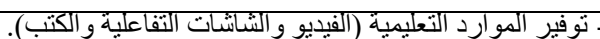

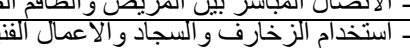

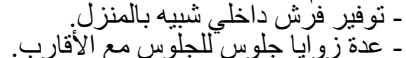

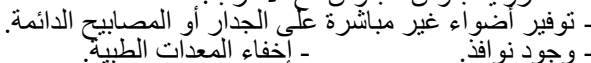
توفير جو شبيه بالمنزل

- استخدام الألوان الزاهية. ـ ـ استخدام الأرضيات الخشبية.

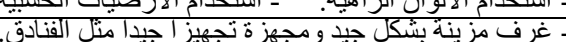

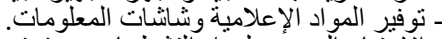

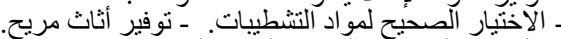

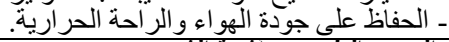

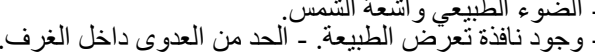




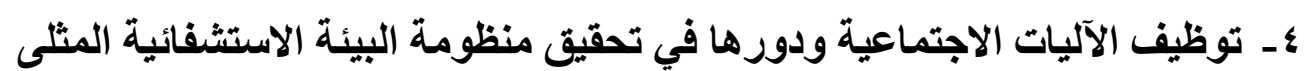

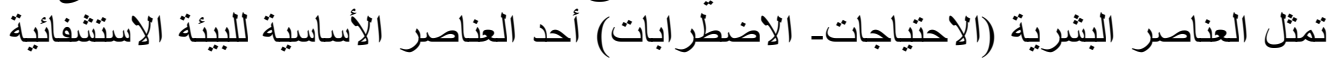

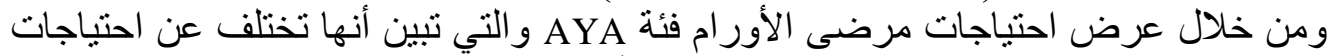

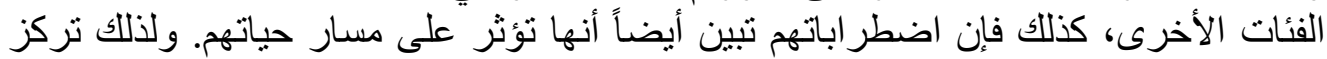

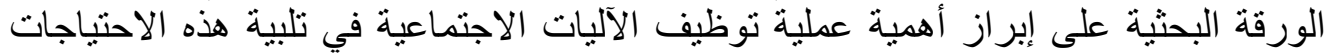

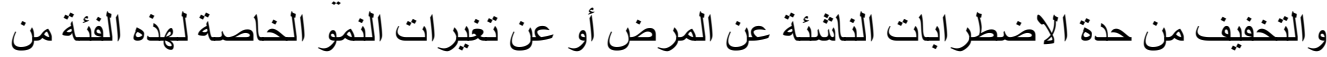

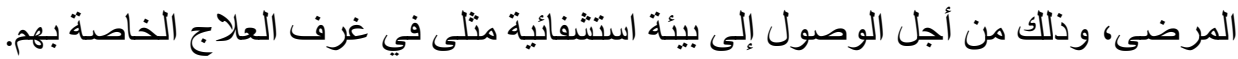

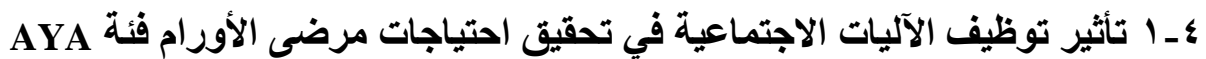

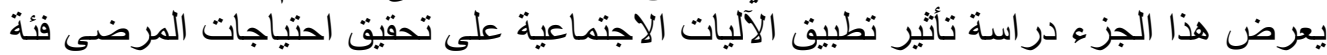

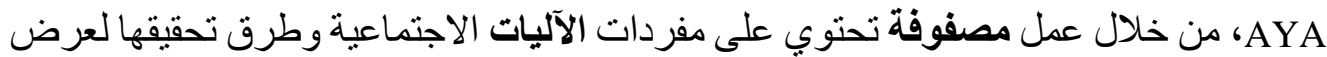

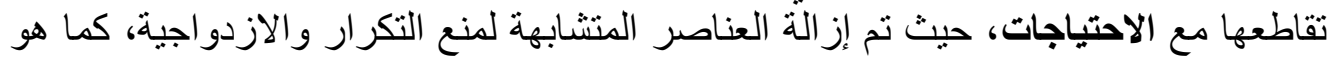

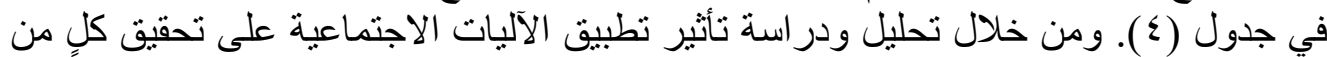
احتياجات مرحلة المر اهقة و البلو غلو واحتياجات مرضى تونى السرطان.

جدول ( ) ): آثر توظيف الآليات الاجتماعية على تحقيق احتياجات المرضى AYA

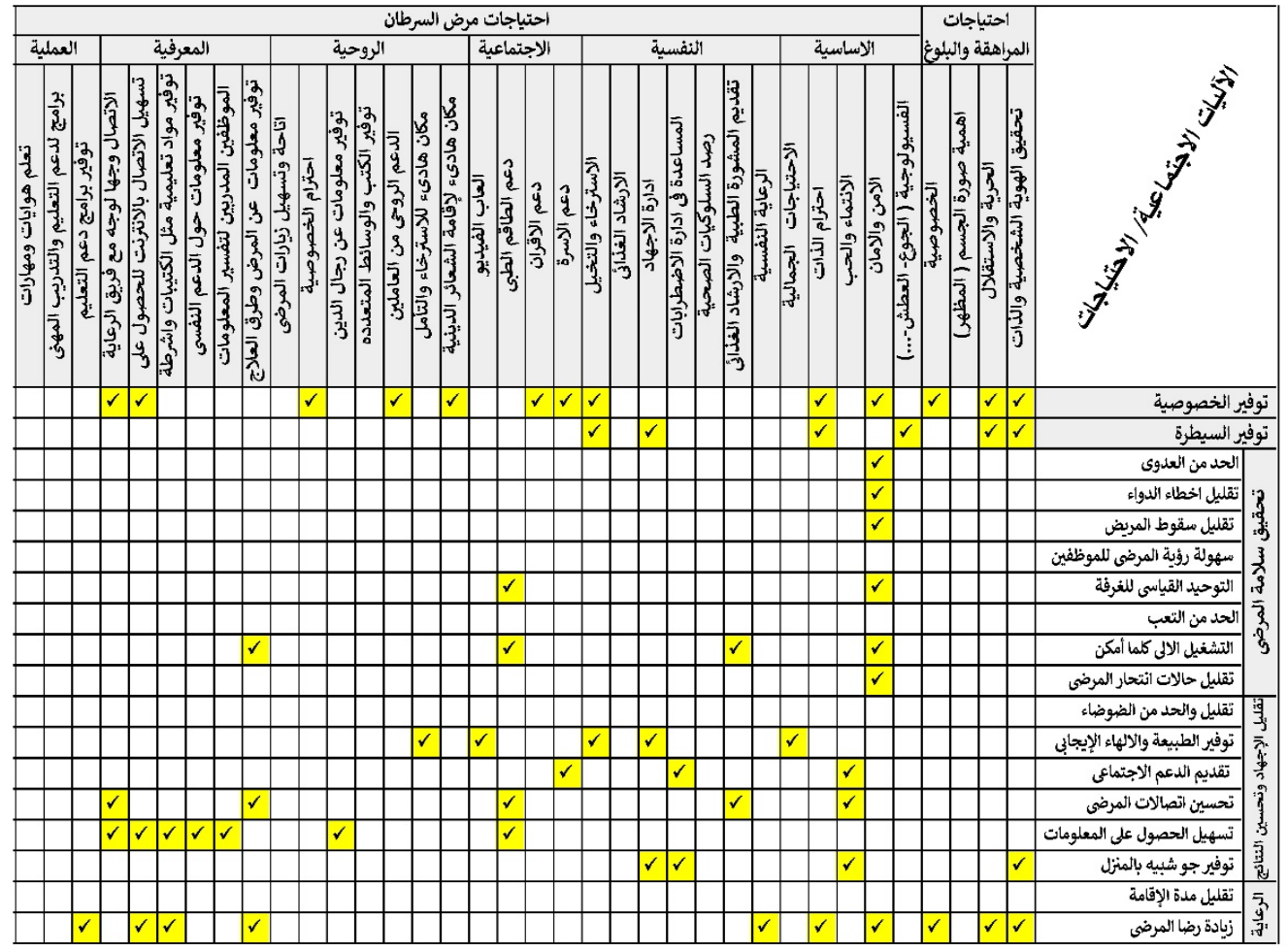

كما يوضح جدول (0) مصفوفة الاحتياجات المختلفة للمرضى فئة AYA و الآليات الاجتماعية

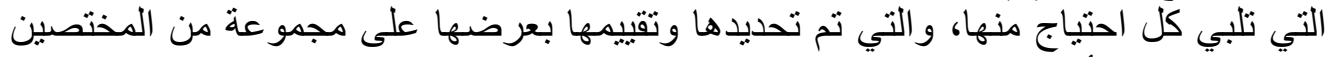

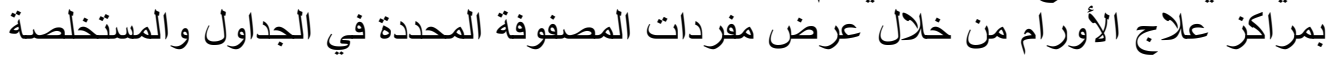
من آراء المتخصصين التي نم اختبار ها من حالات سابقة. 
هاجر حدي، خالد الليثي، نوبي حسن، الآليات الاجتماعية ودورها في تحقيق البيئة الاستشفائية الدثلى لغرف مرضى الأورام

جدول (•): الآليات الاجتماعية التي تعمل على تحقيق احتياجات AYA

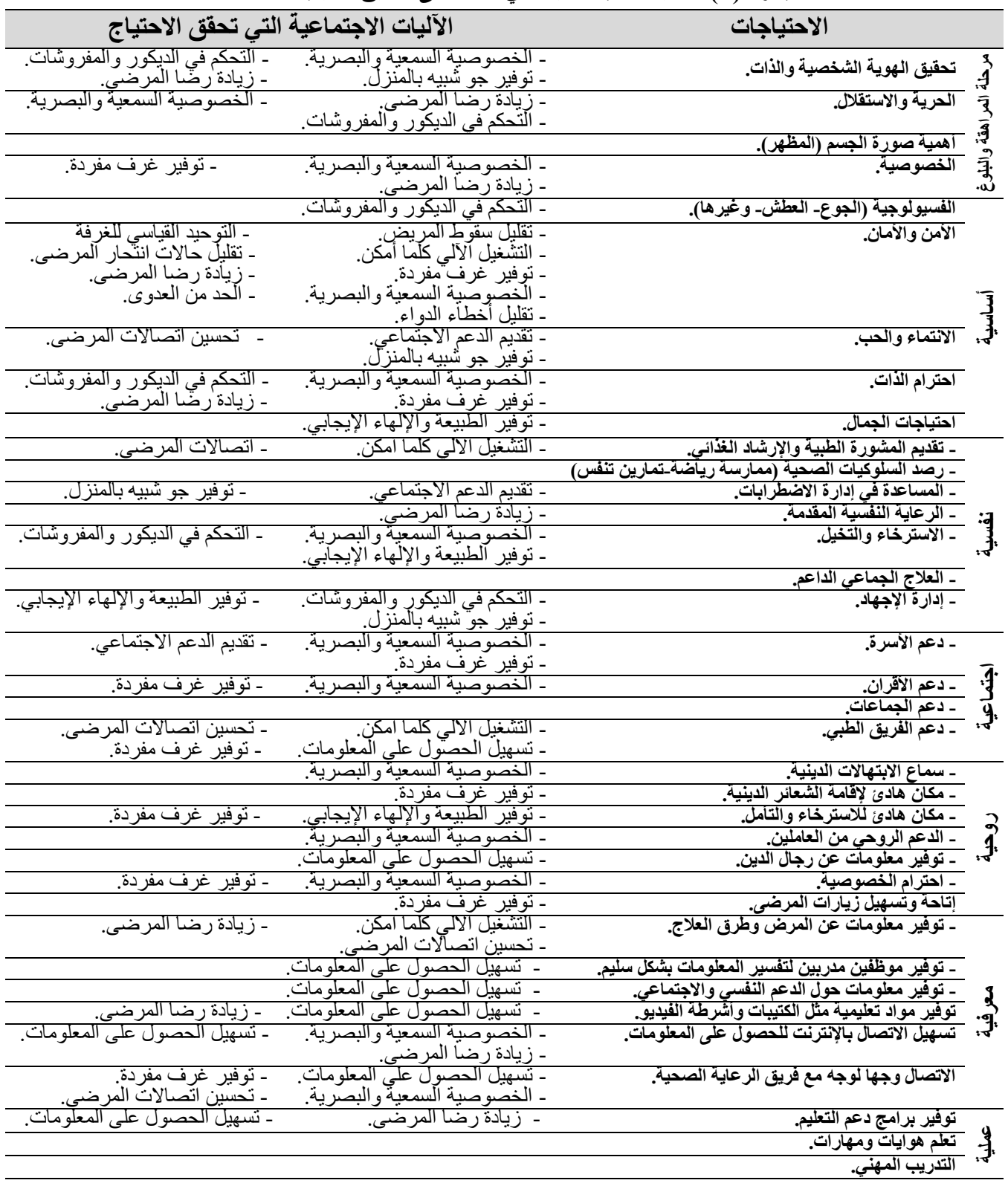

إن احتياج الهوية وتحقيق الذات على سبيل المثال يمكن تحقيقه عن طريق آليات اجتماعية متعددة

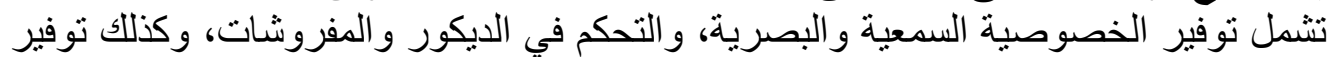

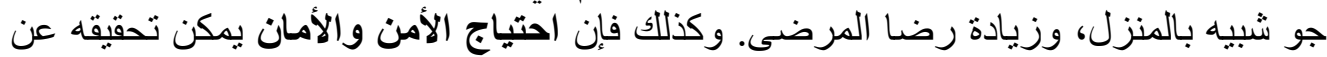

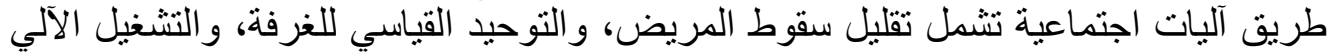

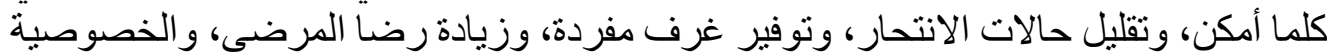

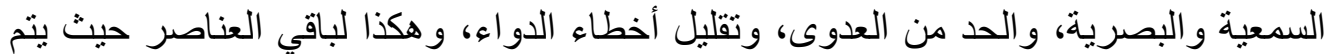

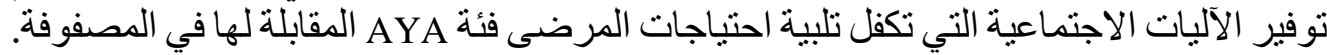




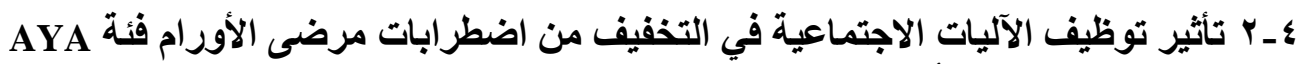

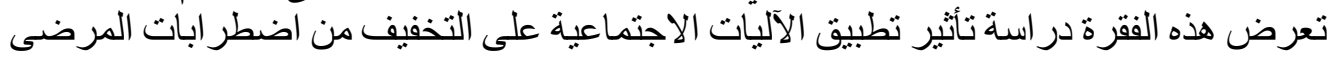

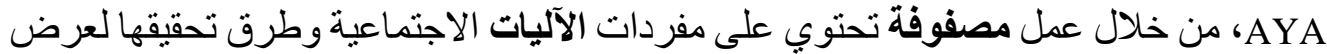

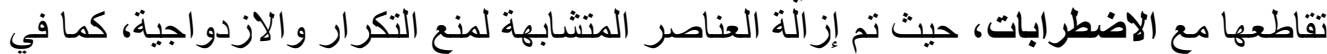

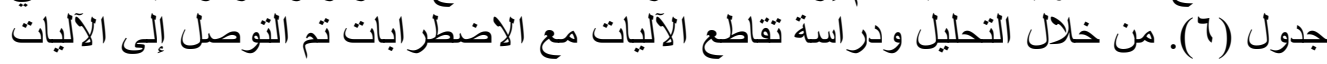

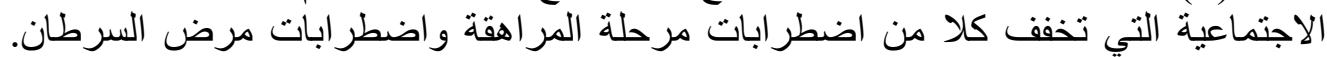

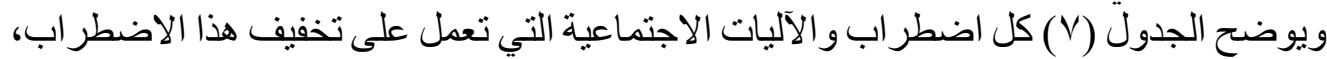

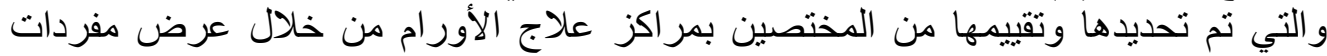
مصفوفة الآليات و التي تم اختبار ها وتقييمها من حالات سابقة.

جدول (†): تأثير توظيف الآليات الاجتماعية على التخفيف من اضطرابات المرضى AYA

\begin{tabular}{|c|c|c|c|c|c|c|c|c|c|c|c|c|c|c|c|c|c|c|c|c|c|c|c|}
\hline & & 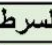 & 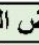 & بمره & بطبة & 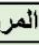 & بات & إنطز & إلالا. & تُار & & & & & & $و^{2}$ & إهة & 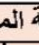 & برح بر & & & & \\
\hline 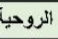 & & تصنادية & & ياعياً & الاجتم & & & & نفف & & & & & & & & & & & & & & को \\
\hline 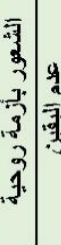 & 桨 & 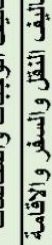 & 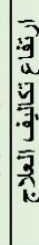 & 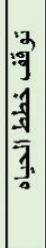 & 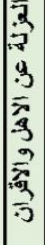 & & . & ; & 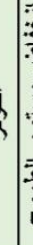 & 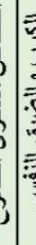 & & 产 & $\frac{\bar{x}}{3}$ & . & $\mid$ & 雱 & $\frac{9}{9}$ & 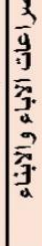 & & & 裔 & 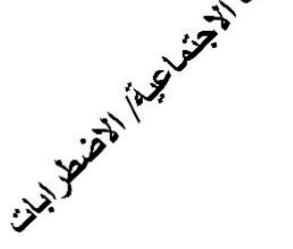 & \\
\hline & & & & & & & & & & & & $\sqrt{v}$ & & & & & & & & & & يزير الخصوصية & \\
\hline & & & & & & & & v & & & $\sqrt{ }$ & & & & & & & & & & & tير النسيطرة & \\
\hline & & & $\checkmark$ & & & & & & & & $\checkmark$ & & & & & & & & & & & | الحذ من العطوى & \\
\hline & & & $\checkmark$ & & & & & v & & & $\checkmark$ & & & & & & & & & & & |تقليلي اخطاء الثواءs & \\
\hline & & & & & & & & & & & $\checkmark$ & & & & & & & & & & & | تقليل سقوط ألمريض & 秥 \\
\hline & & & & & & & & & & & & & & & & & & & & & & | سهولة روية المرضى للموظثقين & 3 \\
\hline & & & $\checkmark$ & & & & & & & & & & & & & & & & & & & التوحيج القياسيى للنغرفة & \\
\hline & & & & & & & & & & & & & & & & & & & & & & |الحد من الثتب & .3 \\
\hline & & & & & & & & & & & & & & & & & & & & & & التشثغيل الالاى كلما أمكن & \\
\hline & & & & & & & & & & & & & & & & & & & & & & تقليل حالاث أنتحار المرضي & \\
\hline & & & & & & & & & & & & & & & & & & & & & & تقليليل والحد من الضوضاء & 误 \\
\hline & & & & & & & & $\mathbf{v}$ & & & $\checkmark$ & & & & & & & & & & & توفيز الطُبعة والالهاء الإيجابي & \\
\hline & & & & & $\nabla$ & & & t & & & & & & & & & & $\checkmark$ & & $\checkmark$ & & تَقَّيمِ الألاعم الاجتماعى & $\frac{7}{2}$ \\
\hline & & & & & & & & & & & & & & & & & & & & & & تحسين اتصالات المرضى & t \\
\hline & & & & & & & $\checkmark$ & & & & $\checkmark$ & & & & & & & & & $\checkmark$ & & تسهيل الحصول على المعنومات & 3 \\
\hline & & & & & & & & & & & $\sqrt{ }$ & & & & & & & & & & & |توفير جو شبيه بائمنزل & 虹 \\
\hline & $\checkmark$ & $7 \sqrt{7}$ & $\checkmark$ & & & & & & & & & & & & & & & & & & & تقليل هدة الإقامة & $\overline{3}$ \\
\hline & & & & & & & $\checkmark$ & $\mathbf{v}$ & & & $\checkmark$ & & & & & & & & & & & ا زيادة رضا المرضى & $-\frac{9}{9}$ \\
\hline
\end{tabular}

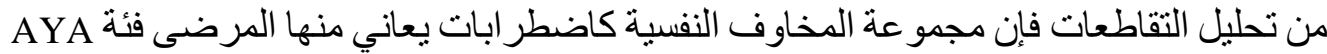

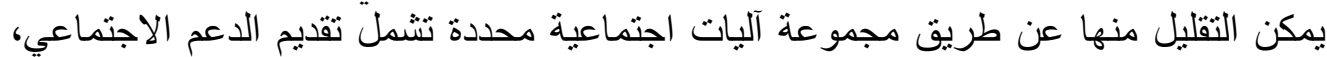

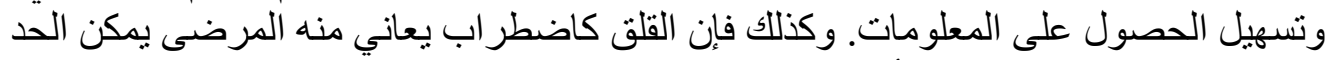

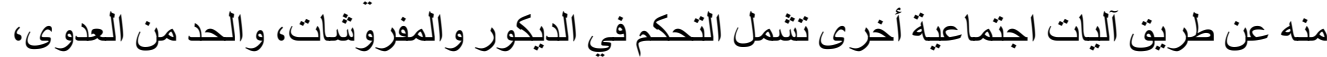

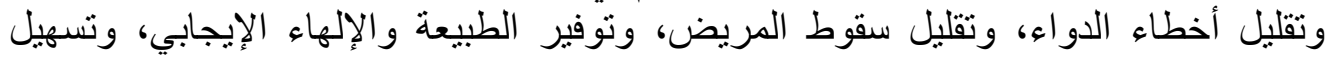

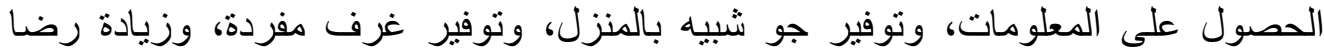

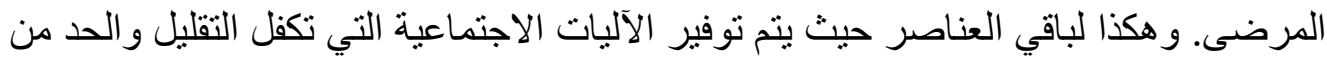
اضطر ابات المرضى فئة AYA المقابلة لها في المصفوفة لالئة 
ATo

هاجر حدي، خالد الليثي، نوبي حسن، الآليات الاجتماعية ودورها في تحقيق البيئة الاستشفائية الدثلى لغرف مرضى الأورام

جدول (V)): الآليات الاجتماعية التى تخفف من اضطرابات AYA

الآليات الاجتماعية التي تخفيف من الاضطر ابط لتئ

الاضطر ابات

ـ الانفعالات الغنيفة.

ـ تسهيل الحصول على المعلومات.

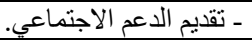

ه

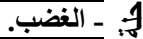

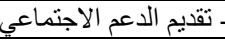

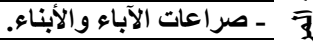

9.8

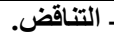

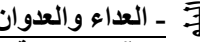

سة. ـ الآلام النفسية.

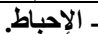

ـ الخصوصية السمعية و البصرية.

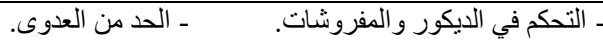

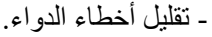

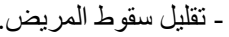

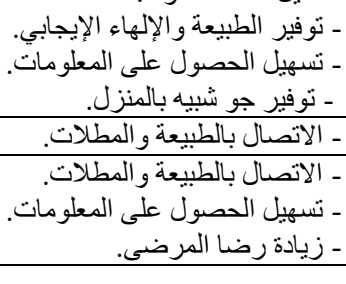

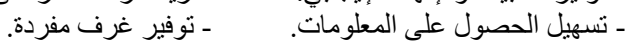

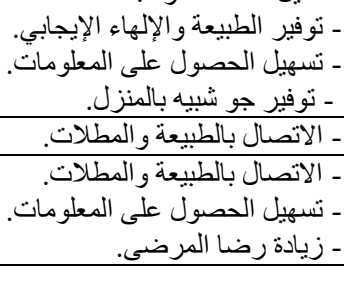

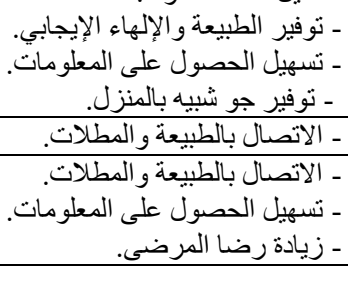

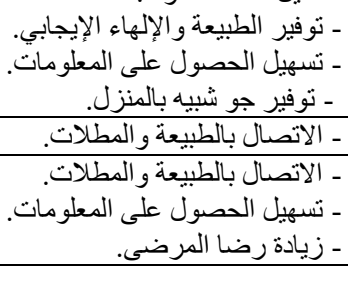

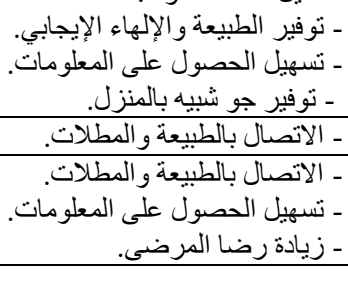

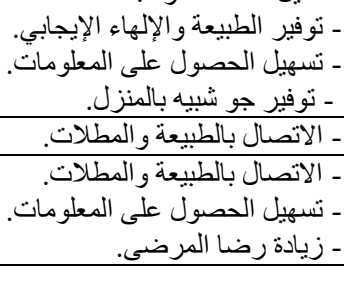

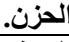

القلثى.

ـ التحكم في الديكور و المفروشات. ـ تقليل أخطاء الدواء.

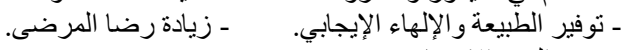

ـ ـ تقديم الدعم الاجتماعي.

ـ الاتصال بالطبيعة و المطنات الاعي.

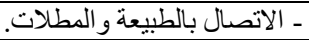

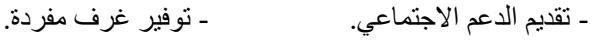

ـ الاتصال بالطبيعة و المطلات. الحد من العدوى.

ـ ـ تقليل أخطاء الدواء.

ـ ـقليل مدة الإقامة.

\begin{tabular}{|c|c|c|}
\hline \multicolumn{3}{|c|}{ ـ غياب المريض عن العمل يسبب مشاكل اقتصادية. } \\
\hline ـ ـ تقليل مدة الإقامة. & ـ الاتصال بالطبيعة و المطلات. & ـ ـ تكاليف النقل والسفر والإقامة. \\
\hline & ـ تقليل مدة الإقامة. & ـ ـ تكاليف الوجبات و المكالمات، \\
\hline & ـ ـ الاتصال بالطبيعة و المطلات. & ـ ـ عدم اليقين. \\
\hline
\end{tabular}

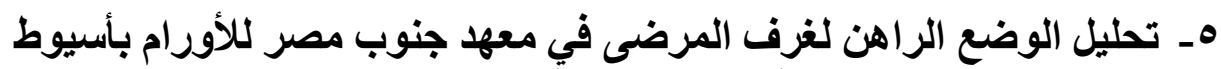

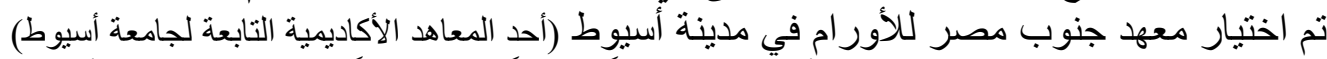

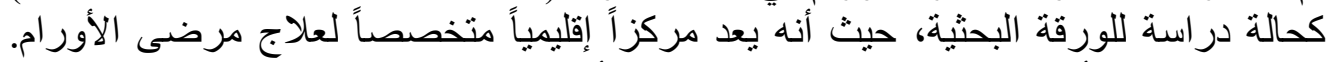

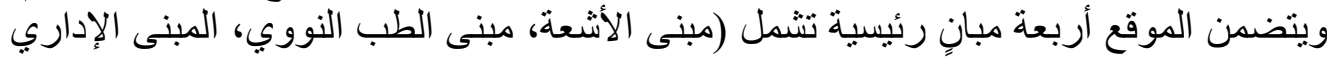

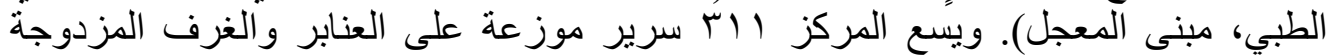

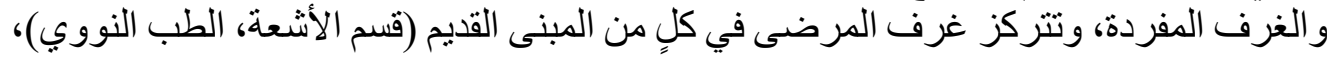
المبنى الجديد (الإداري و والطبي).

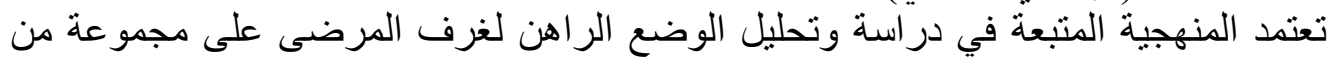

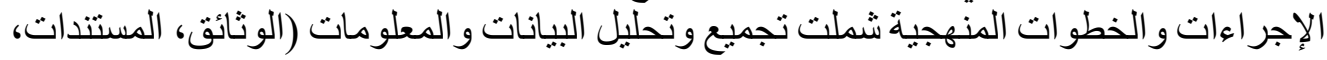




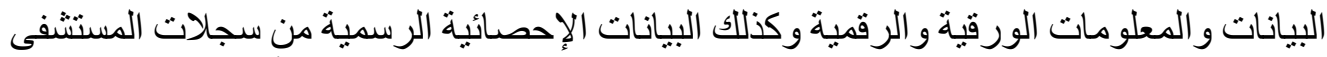

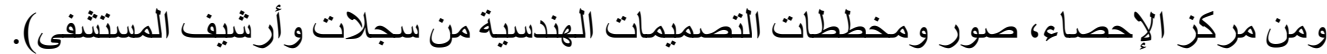

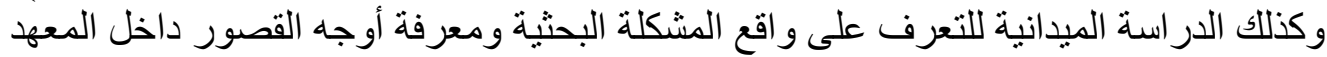

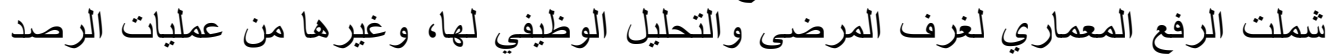

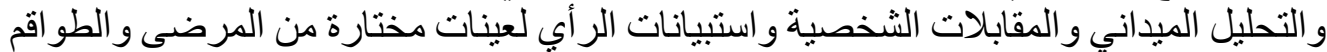

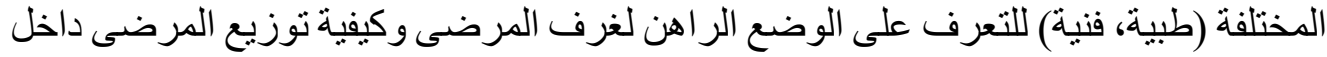

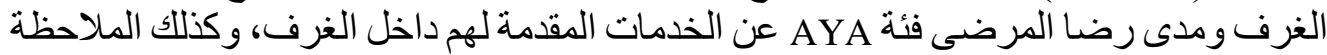

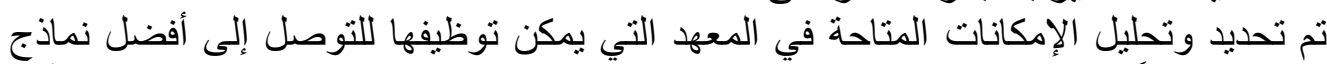

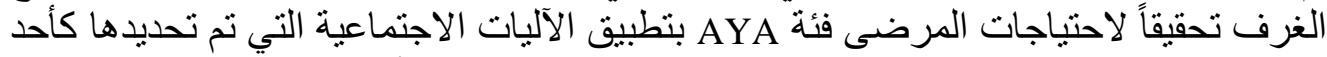

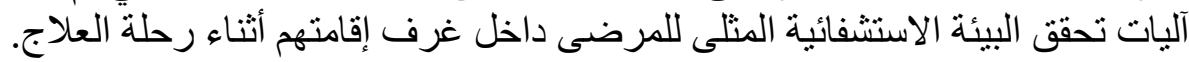

هـ الوفيل استبيانات الرأي لرفع الوضع الراهن

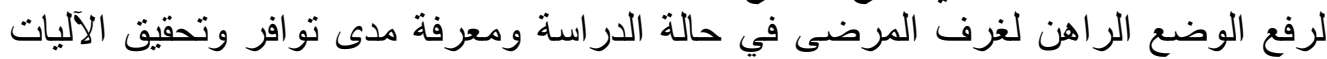

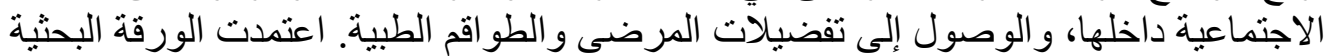

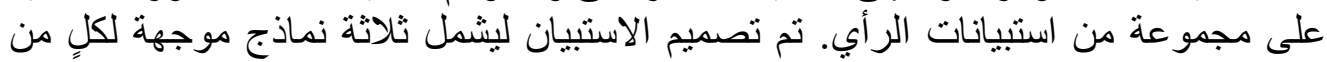

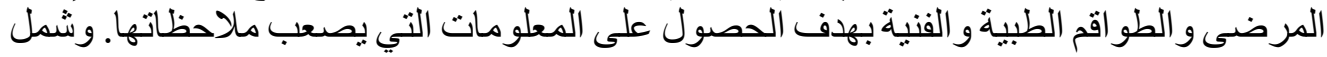

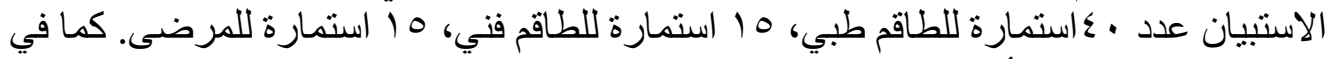

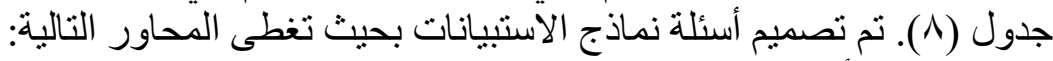

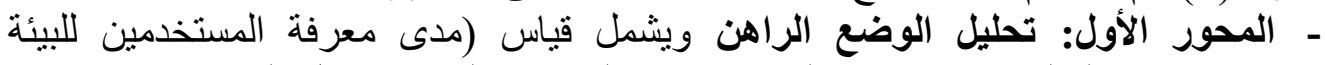

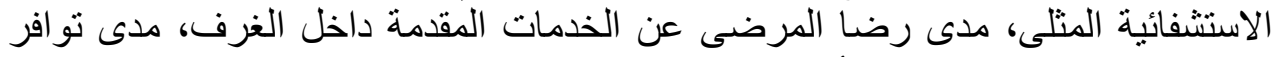

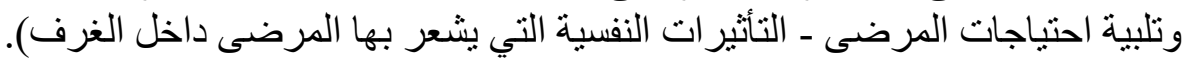
- المحور الثاني: تحديد تفضيلات AYA من الغرف (تفضيلات المرضى و الطو اقم الطبية). جدول (^): توزيع الاستمارات على المستخدمين

\begin{tabular}{|c|c|c|c|c|}
\hline الإجمالي & المرضى & الطاقم القني & الطاقم الطبي & الاستبيانات \\
\hline$v^{\prime}$ & 10 & 10 & $\varepsilon$ & عدد الاستبيانات \\
\hline$\% 1 \ldots$ & $\%$ Y, 0 & $\% Y_{1}, 0$ & $\% \circ \mathrm{V}$ & النسبة \\
\hline
\end{tabular}

هـ ـ ـ ـ ـ ائج استبيانات الرأي في المحور الأول (تحليل الوضع الراهن)

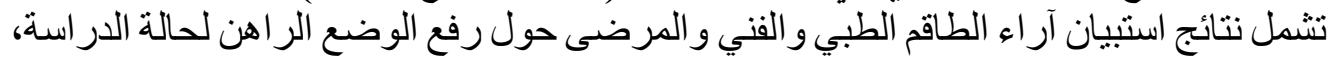
ويمكن توضيح استبيان الآراء في النقاط التالية:

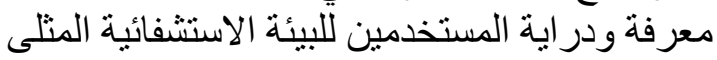

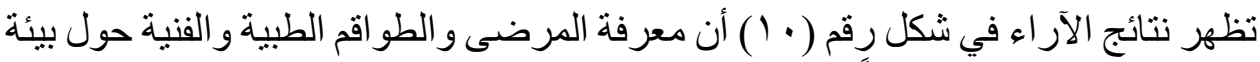
الاستشفاء المثلى ضعيفة جداً.

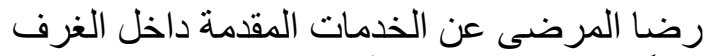

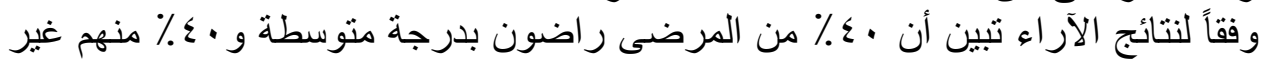

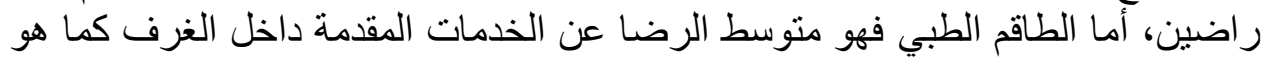


$\Lambda \mathrm{HV}$

هاجر حدي، خالد الليثي، نوبي حسن، الآليات الاجتماعية ودورها في تحقيق البيئة الاستشفائية الدثلى لغرف مرضى الأورام
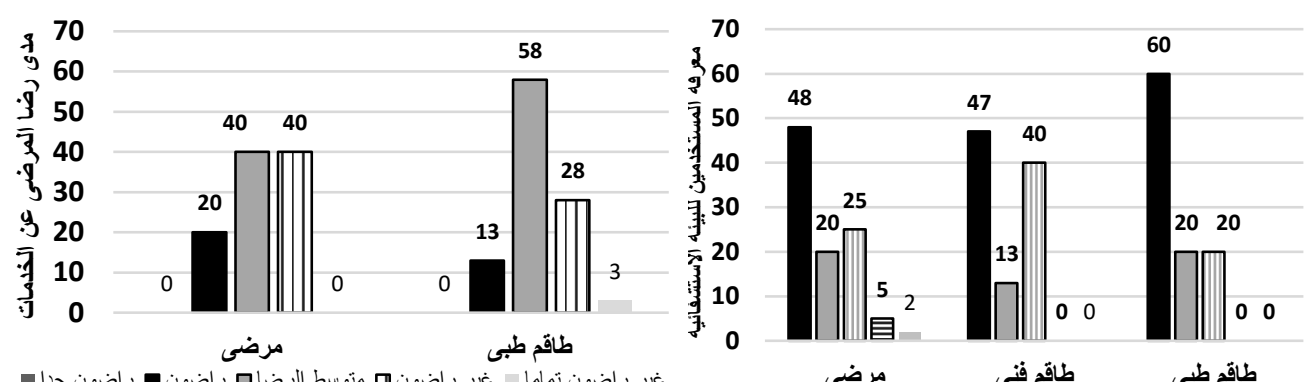

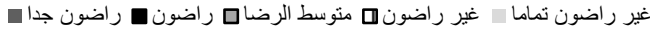

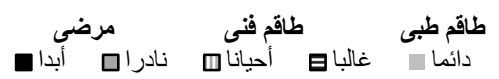

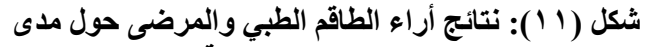

رضا المرضى عن الخدمات المقدمة داخل الغرف الطف

شكل (· · ) : نتائج أراء المرضى والبأ الطاقم الطبي والفني

حول مدى معرفته بالبيئة الاستشفائية المثلى الطي

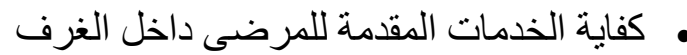

يتو افق ر أي الطاقم الفني و الطبي في أن الخدمات المقدمة للمرضى AYA داخل الخل الغرف غير

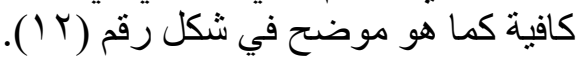

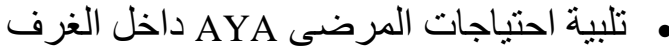

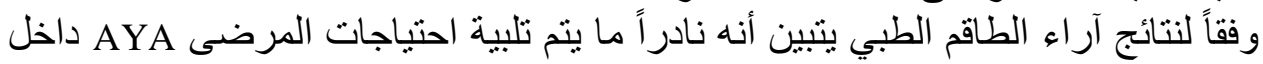

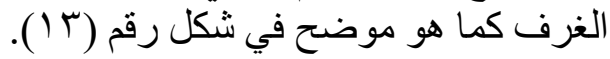

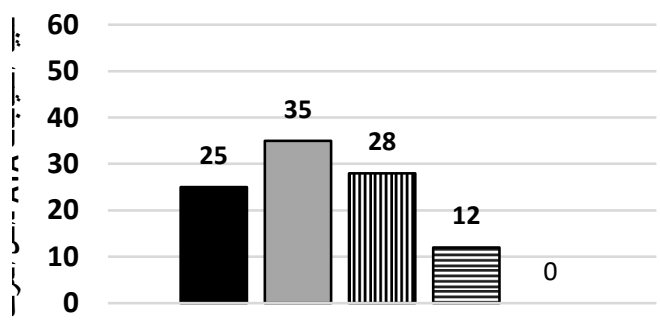

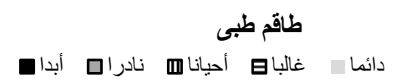

شكل (T I I): نتائج أراء الطاقم الطبي حول مدى تلبية

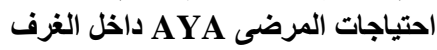

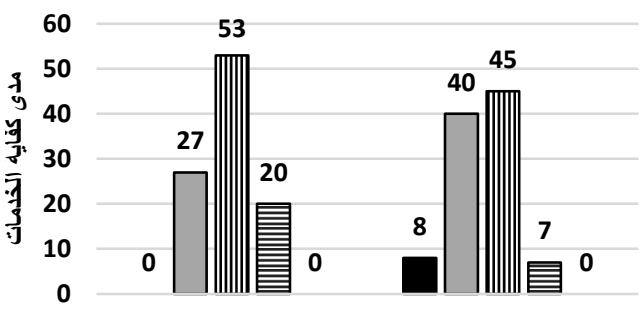

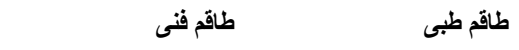

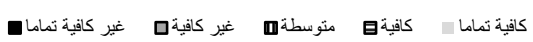

شكل (Y I ): نتائج أراء الطاقم الطبي والفني حول كفاية الخدمات المقدمة للمرضى AYA

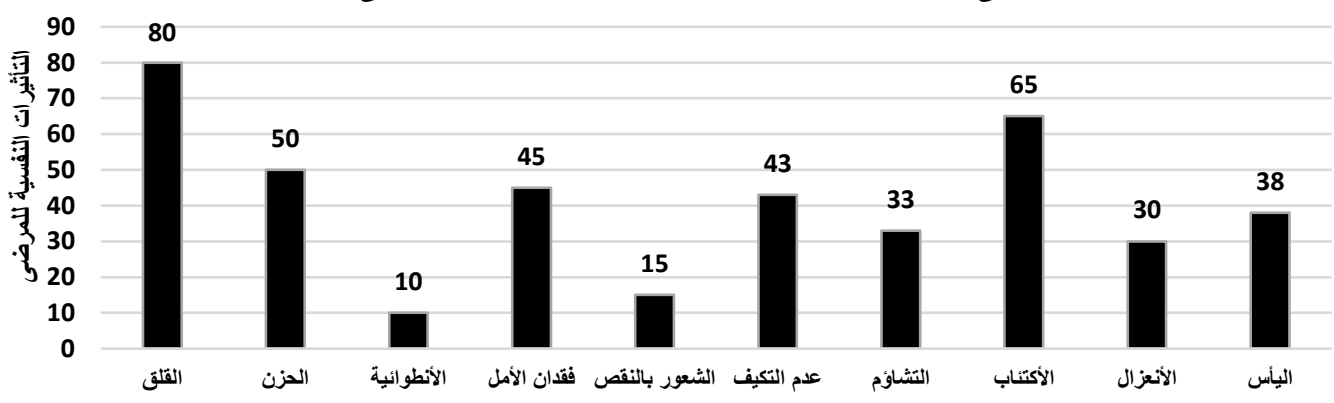

شكل (ع 1): نتائج أراء الطاقم الطبي حول التأثيرات النفسية التي يثعر بها المرضى AYA

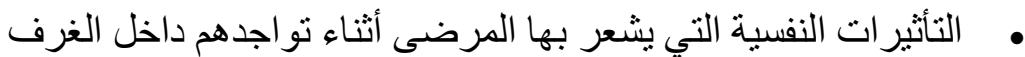

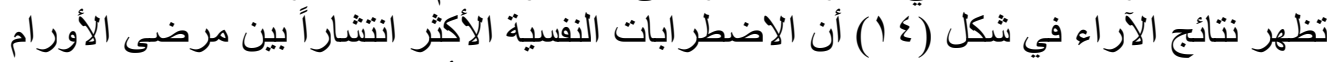

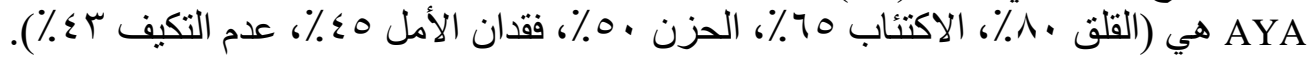




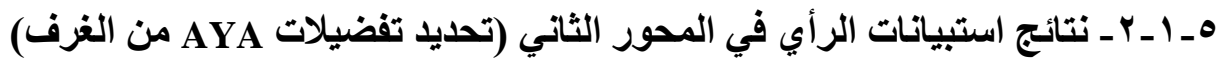

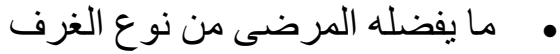

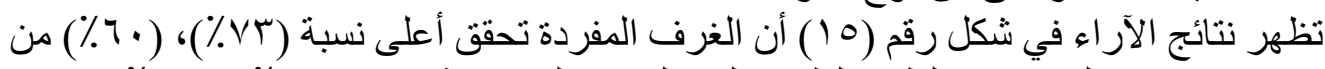

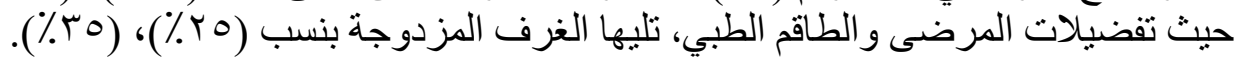

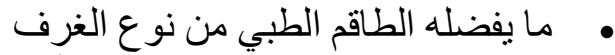

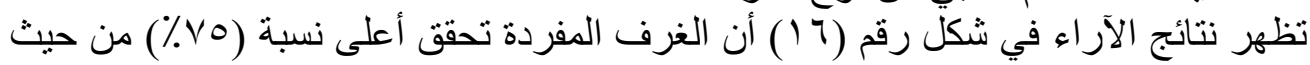
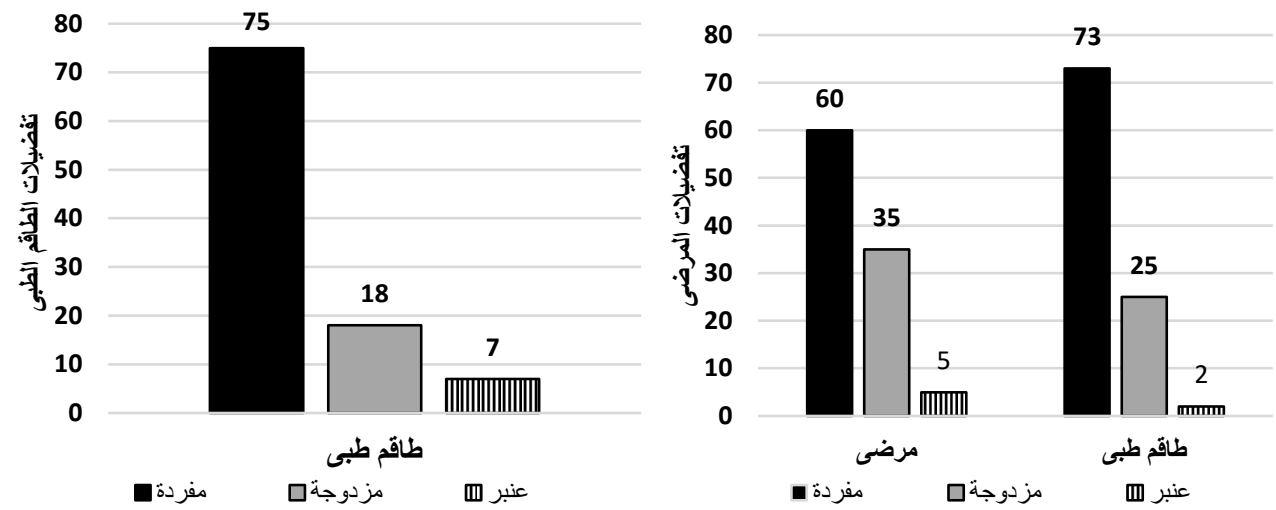

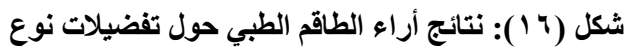
الغرف الطفاق

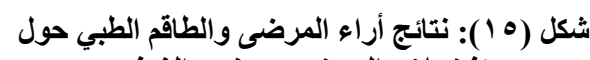
تفضيلات المرضى من نوع أروف الطرف

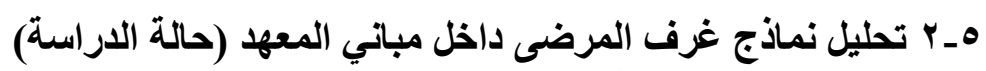

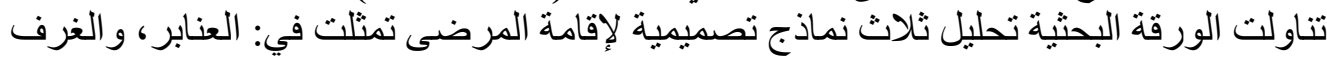

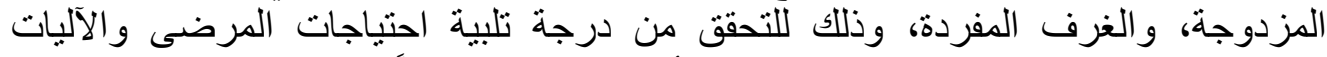

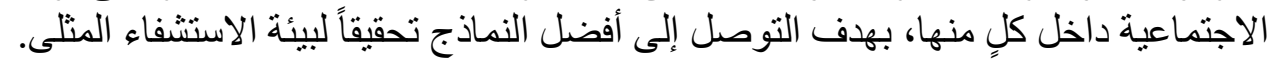

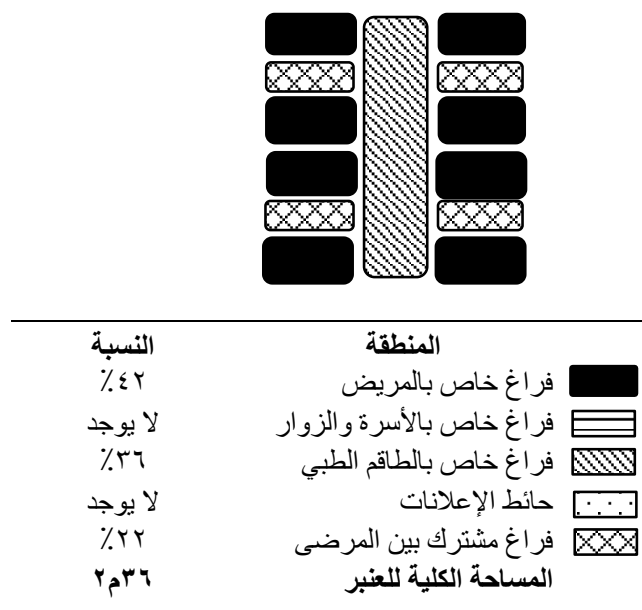

تحليل النموذج الأول (عنبر)

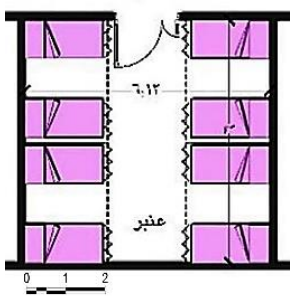

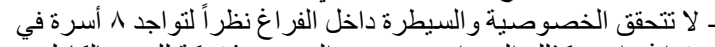

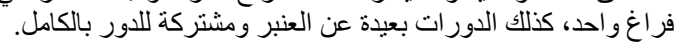

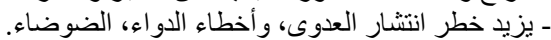

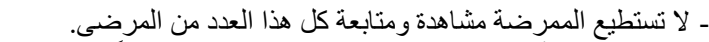

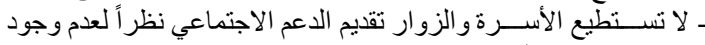

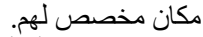
ـ لا تلتوفر الطبيعة أو أي من عناصر الإلهاء الإيجابي داخل العنبر.

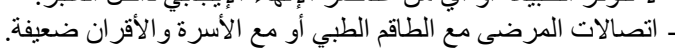




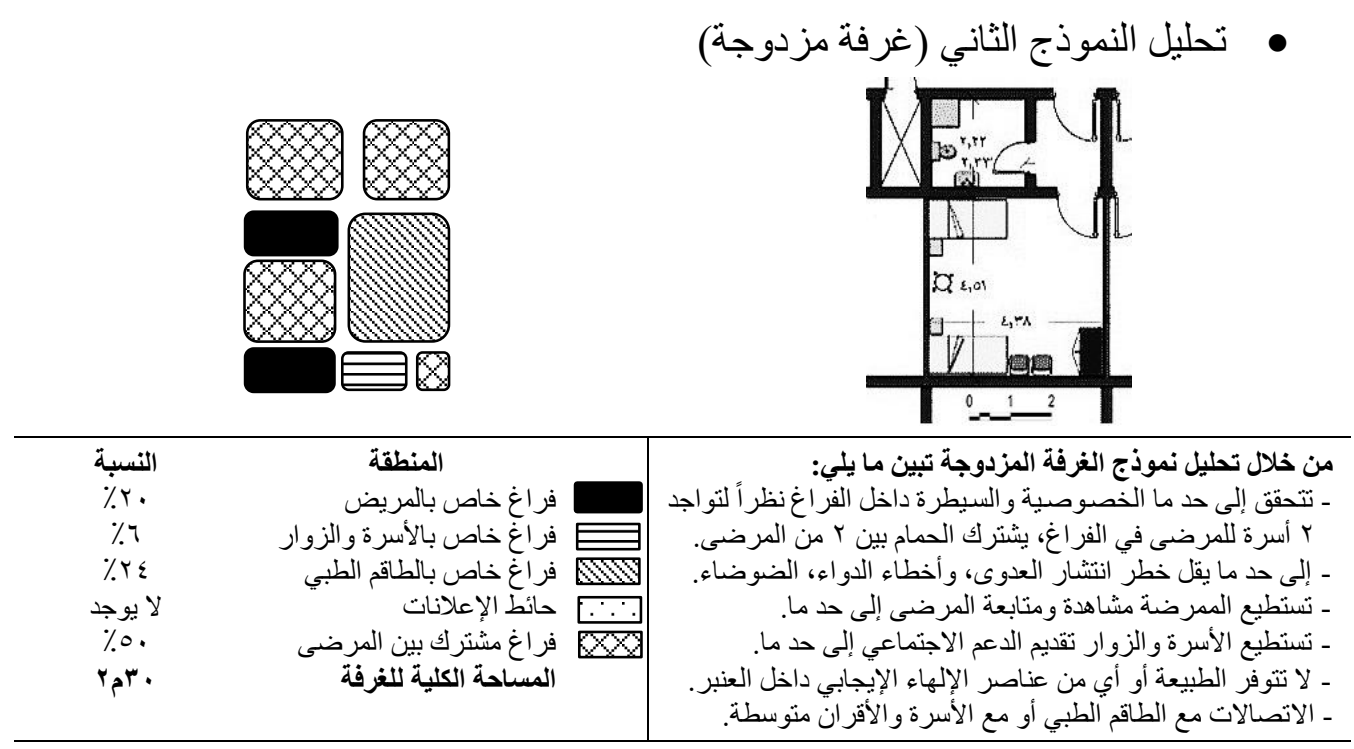

شكل (1) 11): التحليل الوظيفي لنموذج غرفة مرضى مزدوجة

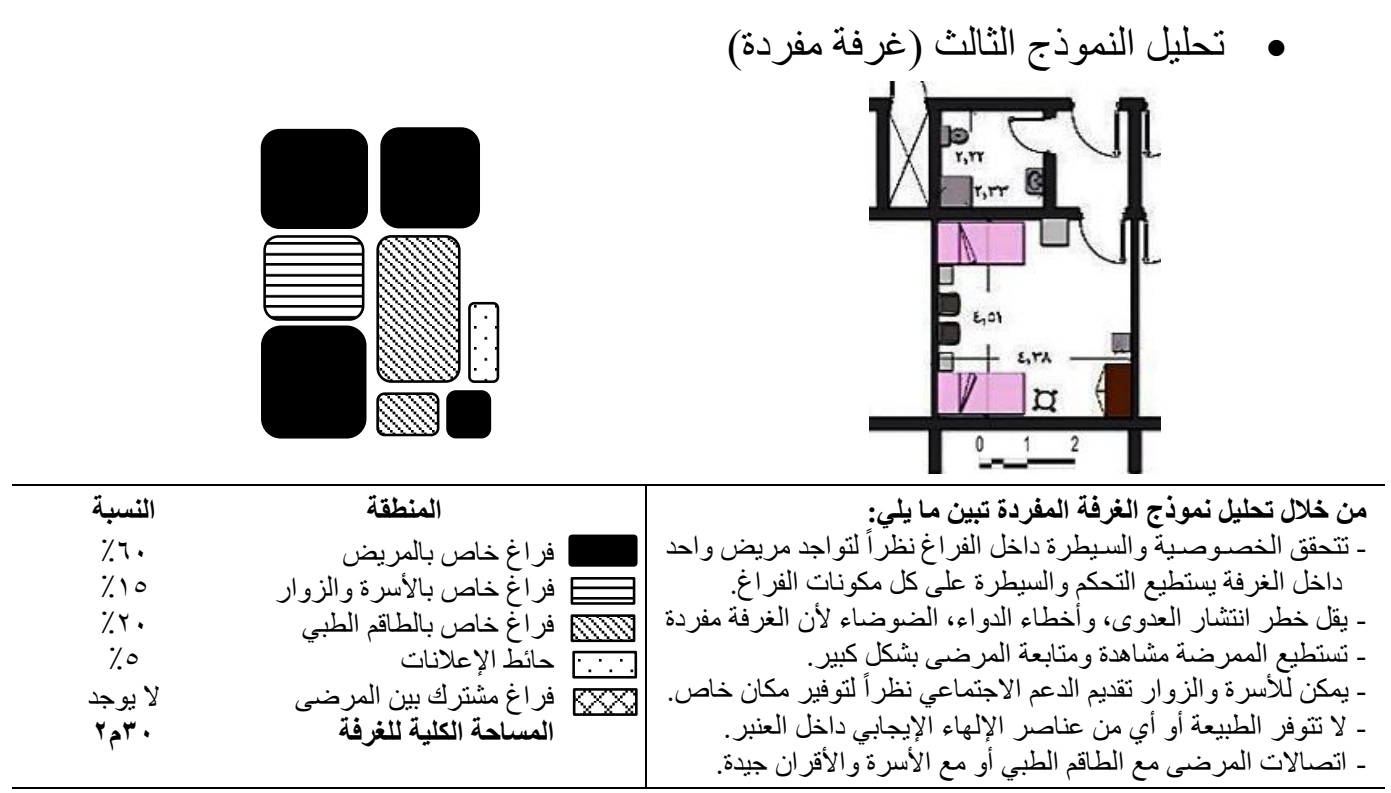

شكل (9 1 ): التحليل الوظيفي لنموذج غرفة مريض مفردة

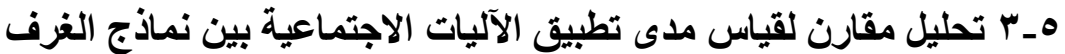

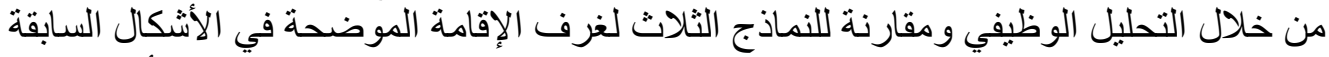

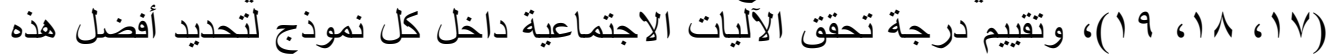

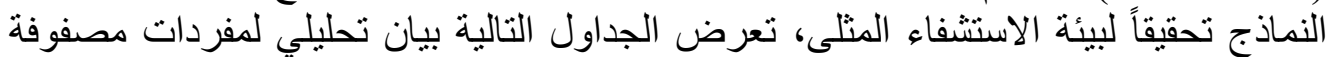

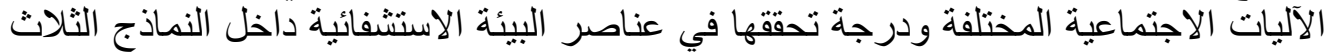
لغرف المرضى، وذلك بعد إز الة العناصر المنتشابهة لهنع الازدو اجية والتكرار. 


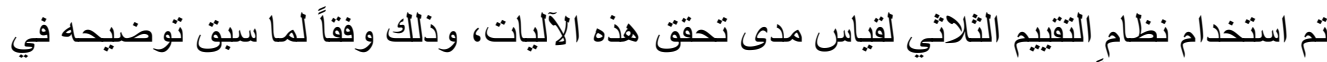

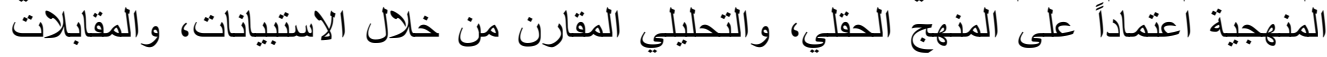

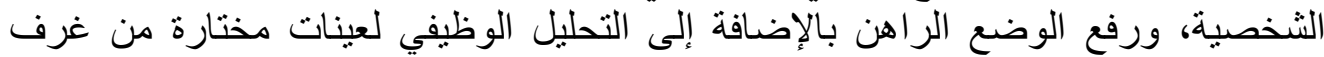

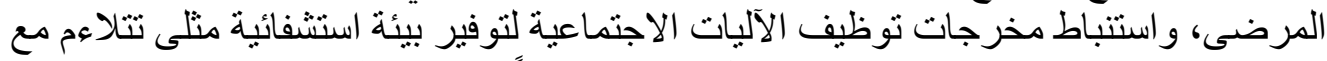

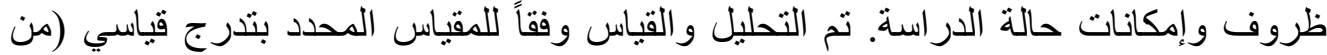

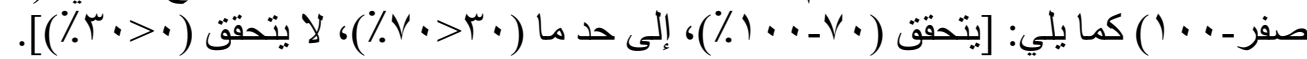

$$
\text { توفير الخصوصية والسيطرة }
$$

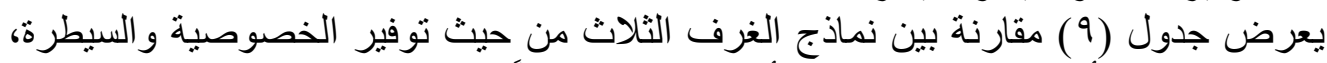

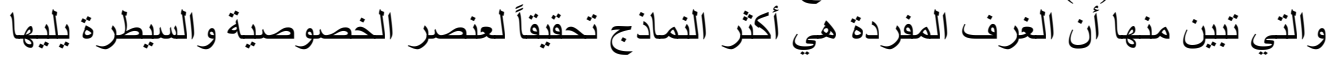

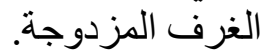

جدول (9) ) درجة تحقيق الخصوصية والسيطرة داخل نماذج الغرف

\begin{tabular}{|c|c|c|c|c|c|c|c|c|c|c|}
\hline \multicolumn{3}{|c|}{ غرفة مفردة } & \multicolumn{3}{|c|}{ غرفة مزدوجة } & \multicolumn{3}{|c|}{ عنبر } & \multirow{2}{*}{ مكونات البيئة الاستثفائية } & \multirow{2}{*}{ الاجتماعية } \\
\hline \multirow[t]{3}{*}{ |لا يتحقق } & إلى حـ ما & تحقق & لا يتحقق & 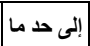 & تحقق & |لا يتحقق & إلى حد ما & تحقق & & \\
\hline & & $\bullet$ & & $\bullet$ & & $\bullet$ & & & ــ الاستقلالية & \multirow{4}{*}{ توفيز } \\
\hline & $\bullet$ & & & $\bullet$ & & $\bullet$ & & & للمريض مساحات لتخزين المتعلقات الثخصية & \\
\hline$\bullet$ & & & $\bullet$ & & & $\bullet$ & & & ـ توفير اتصال بالإنترنت. & \\
\hline \multirow[t]{5}{*}{ - } & & & - & & & - & & & ـــــ رفوف لوضع الصور العائلية. & \\
\hline & & - & & $\bullet$ & & $\bullet$ & & & ــ السيطرة على الديكور و المفروشات & \multirow{10}{*}{ السيطرة } \\
\hline & & $\bullet$ & & $\bullet$ & & $\bullet$ & & & | & \\
\hline & & $\bullet$ & & $\bullet$ & & $\bullet$ & & & ــ التحكم في وضع الأثاث و أماكن الجلوس & \\
\hline & - & & - & & & - & & & ـ المساحة الثخصية ـ أماكن التخزين & \\
\hline - & & & $\bullet$ & & & $\bullet$ & & & ــ الطبيعةـ صور عرض الطبيعة & \\
\hline & $\bullet$ & & $\bullet$ & & & - & & & | وسخائل الإعلام / الأجهزة الإلكترونية & \\
\hline - & & & $\bullet$ & & & $\bullet$ & & & و المرونة يسهل نقله لتحقيق سهوله التنتل & \\
\hline - & & & - & & & - & & & ــ سماعات الرأس لسماع الموسيقى المطلوبة & \\
\hline \multirow[t]{2}{*}{$\bullet$} & & & $\bullet$ & & & $\bullet$ & & & ـ إطار رقمي لعرض الصور العائلية & \\
\hline & - & & & - & & $\bullet$ & & & الثخصية التحكم في وضع التلفزيون و المتعلقات & \\
\hline 7 & $\varepsilon$ & $\varepsilon$ & $\Lambda$ & 7 & . & $1 \leqslant$ & . & . & مجموع العناصر & \\
\hline$\%$ \% & $\% \curlyvee \wedge, 0$ & $\% r \wedge, 0$ & $\% \circ \mathrm{V}$ & $\%$ \% & $\%$ & $\% 1 \ldots$ & $\%$ & $\%$ & نسبة العناصر & \\
\hline
\end{tabular}

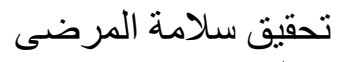

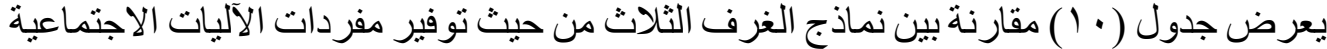

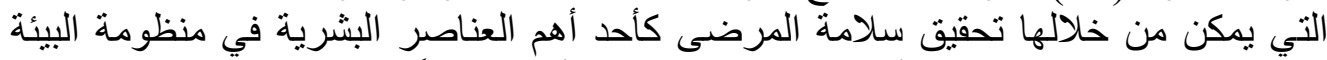

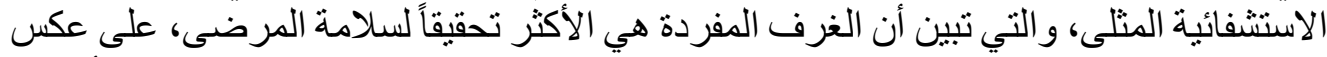

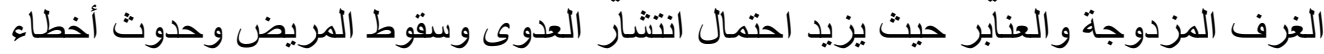
الدو اء و غير ها من المعوقات التي لا تحقق سلامة المرضى وتعوق العير توفير بيئة استشفائية ملائمة

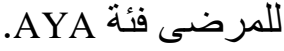


$\Lambda \leq 1$

هاجر حدي، خالد الليثي، نوبي حسن، الآليات الاجتماعية ودورها في تحقيق البيئة الاستشفائية الدثلى لغرف مرضى الأورام

جدول ( • (1): درجة تحقيق سلامة المرضى بين نماذج الغرف

\begin{tabular}{|c|c|c|c|c|c|c|c|c|c|c|}
\hline \multicolumn{3}{|c|}{ غرفة مفردة } & \multicolumn{3}{|c|}{ غرفة مزدوجة } & \multicolumn{3}{|c|}{ عنبر } & \multirow{2}{*}{ مكونات البيئة الاستشفائية } & \multirow{2}{*}{ الاجتماعية } \\
\hline \multirow[t]{5}{*}{ | لا يتحقق } & 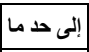 & تحقق & لا يتحقق & إلى حـ ما & تحقق & | لا يتحقق & 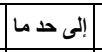 & تحقق & & \\
\hline & & - & & $\bullet$ & & - & & & ـ ـ الحمامات الخاصة & \multirow{8}{*}{ العدوى من } \\
\hline & & $\bullet$ & & & - & & - & & ـ التهوية الجيدة للغرفة & \\
\hline & & $\bullet$ & & • & & - & & & | والتخزين أكبر للغرفة لتسنو عب المعدات & \\
\hline & & $\bullet$ & & & - & & & - & |- مو اد التثطيب سهلة التنظيف & \\
\hline - & & & $\bullet$ & & & $\bullet$ & & & ـ وضع حوض الغسيل بالقرب من الباب & \\
\hline$\bullet$ & & & $\bullet$ & & & $\bullet$ & & & ـ توفير موز عات الكحول للتنظيف & \\
\hline$\bullet$ & & & $\bullet$ & & & $\bullet$ & & & ـ ملصقات لتنكير الموظفين بغسل الأيدي & \\
\hline \multirow[t]{6}{*}{$\bullet$} & & & $\bullet$ & & & $\bullet$ & & & - استخدام مرشحات HEPA & \\
\hline & & - & & & - & & - & & | الإضاءة المناسبة & \multirow{4}{*}{ تقليل أخطاء } \\
\hline & - & & $\bullet$ & & & - & & & | التوحيد القياسي للغرفة & \\
\hline & - & & - & & & - & & & قابلة للتنكييف نقل المرضى بين الغرفــ بغرف & \\
\hline & & - & & • & & • & & & ـ توفير مساحات كافية لأداء العمل & \\
\hline & $\bullet$ & & & - & & - & & & |- وضع الحمامات بجو ار السرير & \multirow{6}{*}{ تقليل سقوط المريض } \\
\hline \multirow[t]{2}{*}{ - } & & & $\bullet$ & & & $\bullet$ & & & ــ أبو اب و اسعة للحمامات & \\
\hline & & - & & & $\bullet$ & & - & & ـــ الإضـاءة الجيدة للغرفة و الحمام & \\
\hline \multirow[t]{3}{*}{$\bullet$} & & & - & & & - & & & ـ تجهيز الحمام بدر ابزين وكر اسي ومقاعد & \\
\hline & - & & $\bullet$ & & & $\bullet$ & & & ـ تجنب الأرضيات الزلقة & \\
\hline & $\bullet$ & & & - & & $\bullet$ & & & 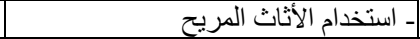 & \\
\hline - & & & - & & & - & & & ـ قرب محطة التمريض من الغرف & \multirow{2}{*}{ للموظلة روئية } \\
\hline - & & & - & & & - & & & بروئة المريض زجاجية للباب تسمح للممرضة & \\
\hline \multirow[t]{2}{*}{$\bullet$} & & & - & & & - & & & | توحيد مناطق المعالجة و المعدات & \multirow{4}{*}{ القياسيّي } \\
\hline & - & & & - & & - & & & head walls توحيد & \\
\hline - & & & - & & & $\bullet$ & & & - تبسيط إعادة تخزين الإمدادات & \\
\hline \multirow[t]{2}{*}{$\bullet$} & & & - & & & $\bullet$ & & & - توحبد السجل الطبي الإكتروني & \\
\hline & & - & & - & & $\bullet$ & & & | ضوضاء أقل & \multirow{2}{*}{ التب من } \\
\hline - & & & - & & & $\bullet$ & & & - استخدام الأرضيات المطاطية & \\
\hline$\bullet$ & & & $\bullet$ & & & $\bullet$ & & & _السجلات الطيبة الإلكترونية. & \multirow{3}{*}{ الآلي كلما } \\
\hline$\bullet$ & & & $\bullet$ & & & $\bullet$ & & & ــار التزميز. . & \\
\hline$\bullet$ & & & - & & & - & & & في الغرفية كمبيوتر في محطة التمريض، & \\
\hline \multirow[t]{3}{*}{$\bullet$} & & & - & & & - & & & | استخدام قضبان الستائر الدوارة & \multirow{4}{*}{ تقليل حالات المار } \\
\hline & & - & & - & & & - & & 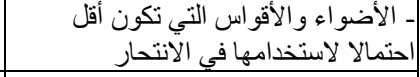 & \\
\hline & - & & - & & & $\bullet$ & & & | زليادة رؤية الموظفين للمرضى طول & \\
\hline - & & & $\bullet$ & & & $\bullet$ & & & |- نو افذ يصعب فتحهاي & \\
\hline 11 & v & 9 & rr & $\wedge$ & $\varepsilon$ & rq & $\varepsilon$ & 1 & مجموع العناصر & \\
\hline$\%$ & $\% r_{\cdot}, 0$ & $\%$ \%४, & $\%$ & $\% r r, 0$ & $\% 11,0$ & $\% \wedge \theta, 0$ & $\% 11,0$ & $\%$ & نسبة العناصر & \\
\hline
\end{tabular}

\section{تحسين النتائج الصحية للمرضى وتحسين جودة الرعاية}

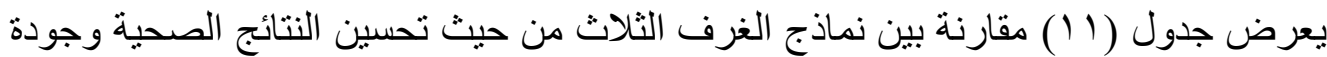

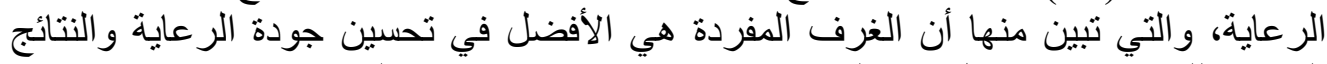

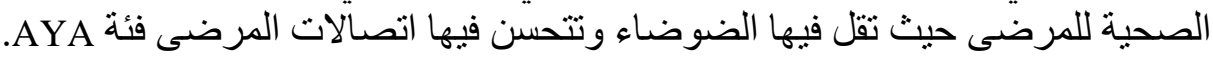


جدول (1 1) ): درجة تحسين النتائج الصحية وجودة الرعاية الصحية لنماذج الغرف

\begin{tabular}{|c|c|c|c|c|c|c|c|c|c|c|}
\hline \multicolumn{3}{|c|}{ غرفة مفردة } & \multicolumn{3}{|c|}{ غرفة مزدوجة } & \multicolumn{3}{|c|}{ عنبر } & \multirow{2}{*}{ مكونات البيئة الاستشفائية } & \multirow{2}{*}{ 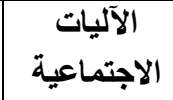 } \\
\hline |لا يتحقق & إلى حد ما & تحقق & لا يتحقق & 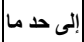 & تحقق & لا يتحقق & [ إبى حد ما & تحقق & & \\
\hline \multirow[t]{2}{*}{$\bullet$} & & & $\bullet$ & & & $\bullet$ & & & ـ مو اد تثنطيب عازلة للصوت & \multirow{3}{*}{ من الضوضل والحاء } \\
\hline & & - & & - & & $\bullet$ & & & إناحة فرص الاستماع الى الموسيقى المهئة & \\
\hline - & & & - & & & $\bullet$ & & & ـ اعتماد نظام استد عاء لا يسبب ضوضاء & \\
\hline$\bullet$ & & & $\bullet$ & & & $\bullet$ & & & ـ استخدام الفن & \multirow{4}{*}{ توفير الطبيعة } \\
\hline - & & & $\bullet$ & & & $\bullet$ & & & ـ شريط يعرض الطبيعة (زهور - أثجار - مياه..) & \\
\hline$\cdot$ & & & $\bullet$ & & & $\bullet$ & & & ـ استخدام اللوحات الحائطية و المطبو عات . & \\
\hline \multirow[t]{4}{*}{$\bullet$} & & & - & & & - & & & |لورقية) استخدام عناصر الترفيه (الألغاز - الألعاب & \\
\hline & - & & & - & & - & & & ــ المراحيض الوصول الى المواد الغذائية و الهو اتف & \multirow{4}{*}{ تقليم الدعم } \\
\hline & & - & & - & & $\bullet$ & & & ـ النوم) مسير مساحة مخصصة للأسرة (للجلوس & \\
\hline & & - & & - & & - & & & 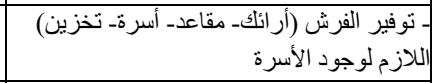 & \\
\hline \multirow[t]{2}{*}{$\bullet$} & & & - & & & $\bullet$ & & & ــ مساحة مرنه للأنشطة التي يقوم بها المريض & \\
\hline & & - & & - & & $\bullet$ & & & | ل الاستقلالية & | \\
\hline - & & & - & & & - & & & 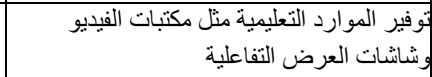 & \multirow{5}{*}{ 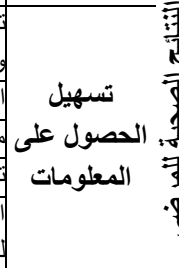 } \\
\hline - & & & - & & & - & & & استخدام مقاطع الفيديو و الكتب & \\
\hline$\bullet$ & & & $\bullet$ & & & $\bullet$ & & & مجمو عات الدعم عن طريق مواقع الإنترنت & \\
\hline \multirow[t]{2}{*}{$\bullet$} & & & - & & & - & & & توفير برامج التثقيف الصحي & \\
\hline & & - & & & - & $\bullet$ & & & لالاتصهال لتلقى المباشر بين المريض و الطاقم الطبي & \\
\hline - & & & - & & & - & & & |لـنية و النبامتات الداخلية والزخارف و السجاد و الأعمال & \multirow{8}{*}{ شبيه بالمنزل } \\
\hline - & & & - & & & - & & & ـ توفير فرش داخلي شبيه بالمنزل & \\
\hline - & & & $\bullet$ & & & $\bullet$ & & & ـــــإتاحة توفير المشروبات داخل الغرفة & \\
\hline$\bullet$ & & & $\bullet$ & & & $\bullet$ & & & ـ عدة زو ايا جلوس للجلوس مع الأقارب . & \\
\hline$\bullet$ & & & $\bullet$ & & & $\bullet$ & & & 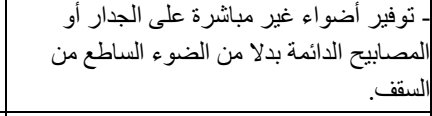 & \\
\hline - & & & - & & & - & & & ــــــاء المعدات الطبية & \\
\hline$\bullet$ & & & $\bullet$ & & & $\bullet$ & & & ل استخدام الألو ان الزاهية & \\
\hline \multirow[t]{3}{*}{$\bullet$} & & & $\bullet$ & & & $\bullet$ & & & ــ استخذام الأرضيات الخشبية & \\
\hline & & - & & & - & & - & & 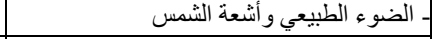 & \multirow{2}{*}{ الإقامة مدة } \\
\hline & & $\bullet$ & & - & & - & & & 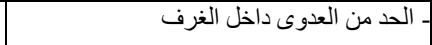 & \\
\hline \multirow[t]{3}{*}{ - } & & & - & & & - & & & | غلفنادق مزينة بشكل جيد ومجهزة جيدا مثل & \multirow{5}{*}{ زايادة رضى المرضى } \\
\hline & & - & - & & & - & & & ـ توفير المو اد الإعلامية وشاشات المعلومات & \\
\hline & - & & & - & & $\cdot$ & & & - الاختيار الصحيح لمواد الثنثطيبات & \\
\hline \multirow[t]{2}{*}{ - } & & & - & & & $\bullet$ & & & ـتوفير أثاث مريح & \\
\hline & & - & & - & & - & & & ــ الحفاظ على جودة الهو اءو والر احة الحرارية & \\
\hline rl & r & 9 & rr & $\wedge$ & r & $r$ & 1 & - & مجموع العناصر & \\
\hline$\% 90,0$ & $\%$ & $\%$ \% & $\% \neg \Lambda, 0$ & $\%$ ro & $\% 4$ & $\% 9 \mathrm{~V}$ & $\%$ & $\%$ & نسبة العناصر & \\
\hline
\end{tabular}




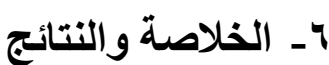

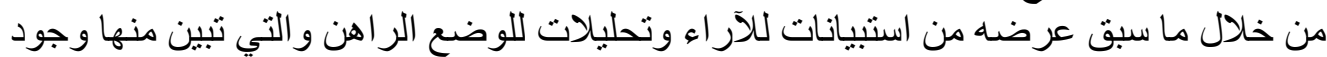

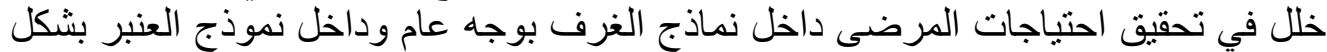

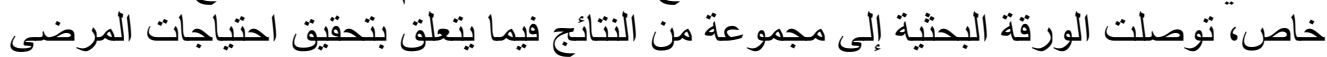
AYA

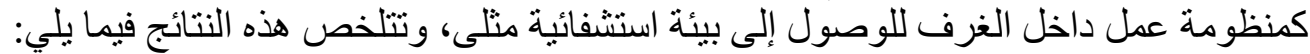

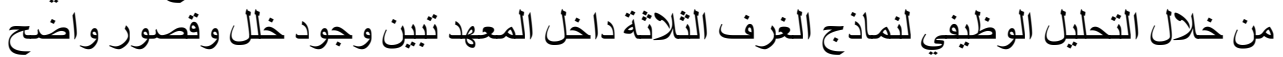

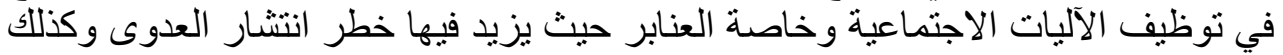

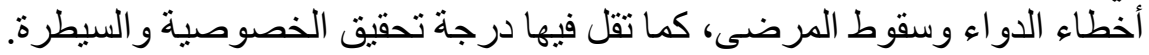

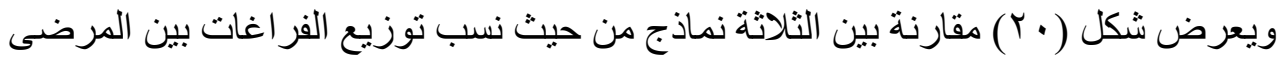

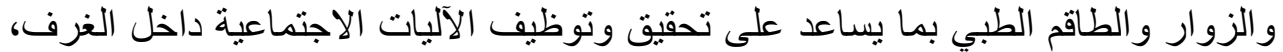
و الذي يظهر منها أن الغرف المفردة هي الأفضل في توزيع نسب الفر الفرات الاتيات

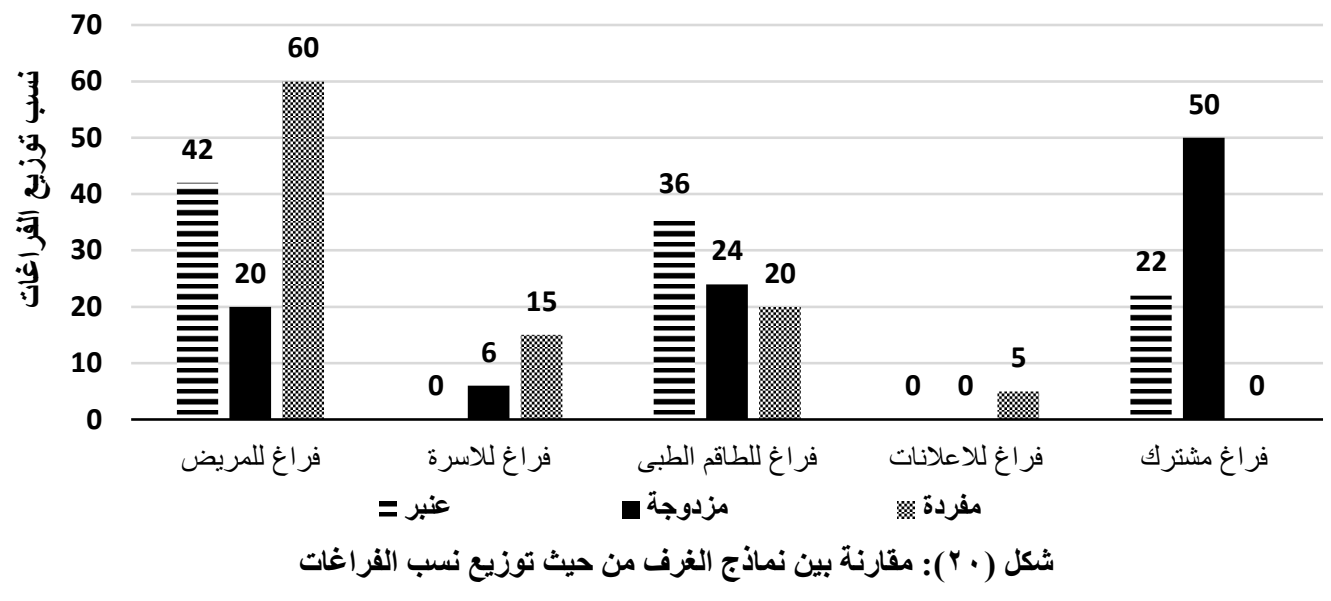

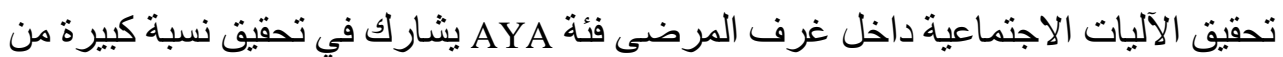

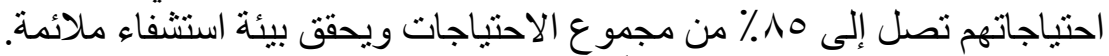

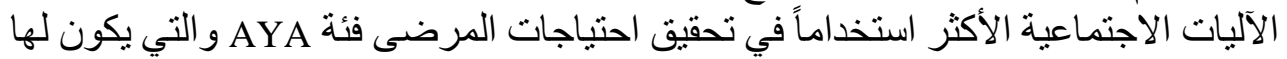

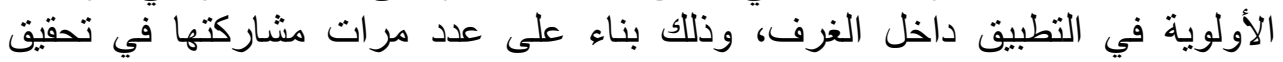

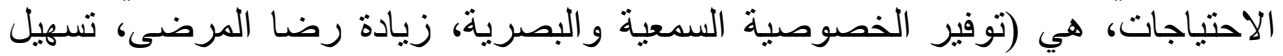

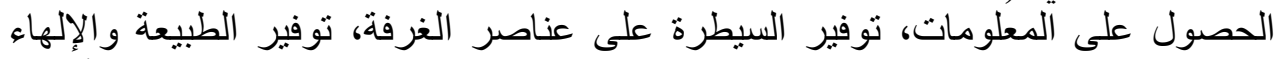

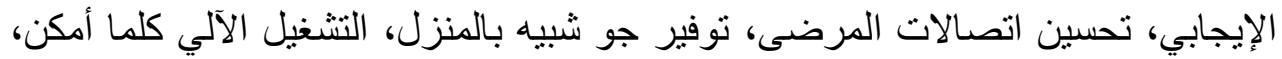

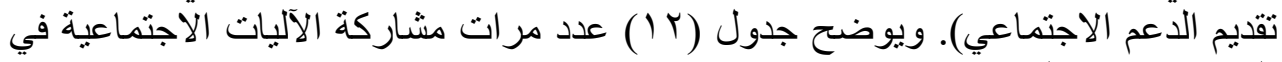

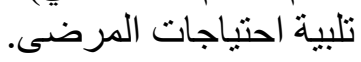

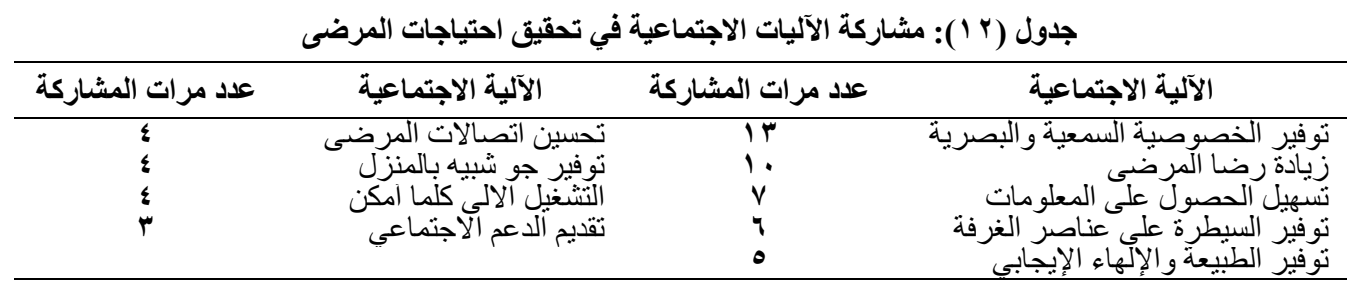




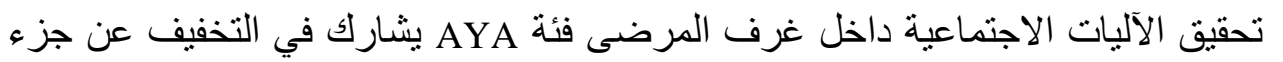

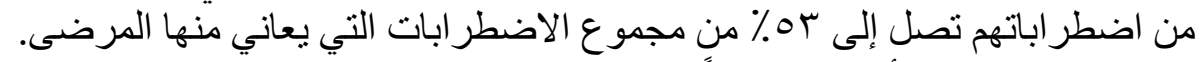

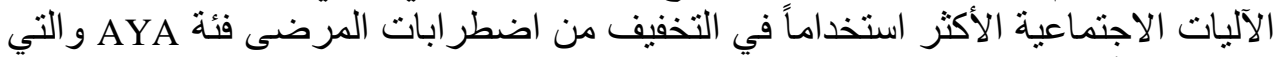

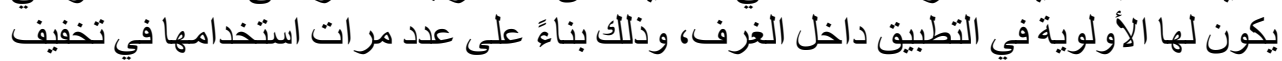

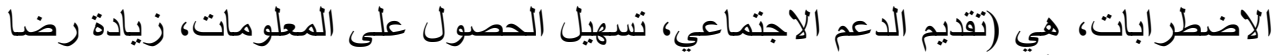

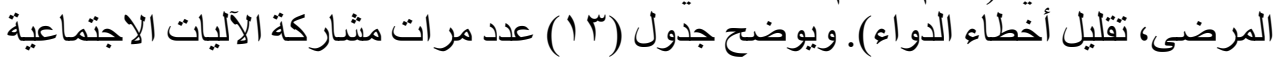
في تخفيف اضطر ابات المرضى. لألئ.

جدول (" ا ) : مشاركة الآليات الاجتماعية فى تخفيف اضطر ابات المرضى

\begin{tabular}{|c|c|c|c|}
\hline عدد مرات المشاركة & الآلية الاجتماعية & عدد مرات المشاركة & الآلية الاجتماعية \\
\hline$r$ & تقليل أخطاء رضا الدوضى & $\xi$ & 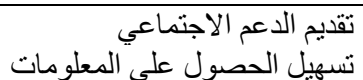 \\
\hline
\end{tabular}

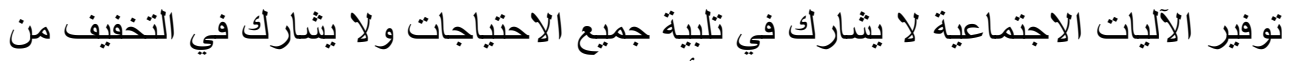

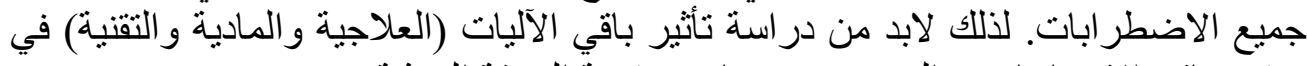

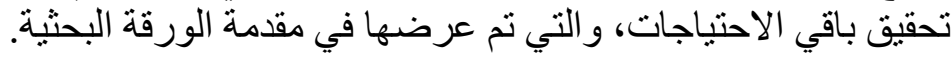

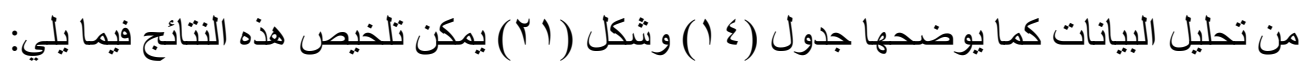

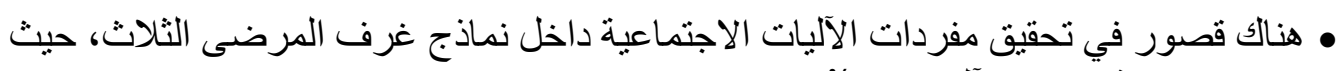

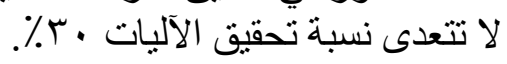

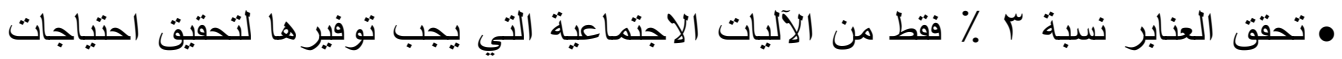

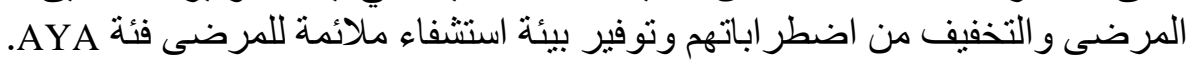

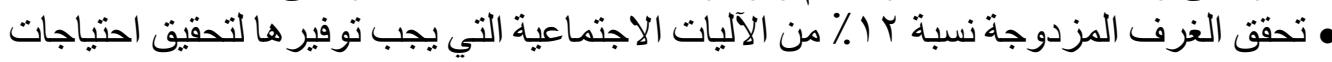

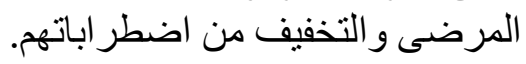

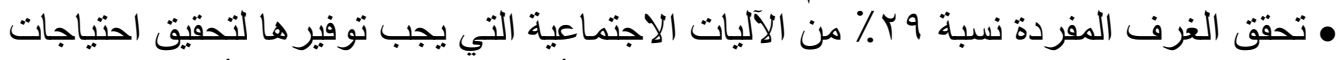

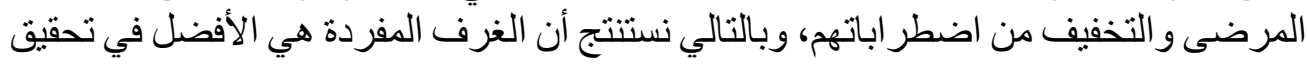

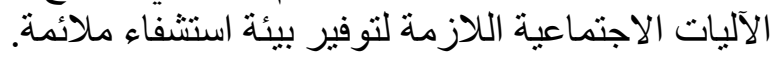

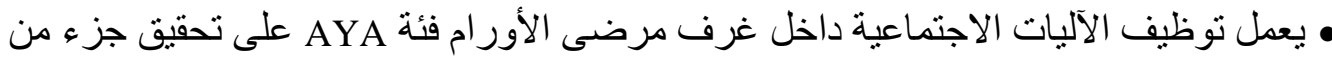

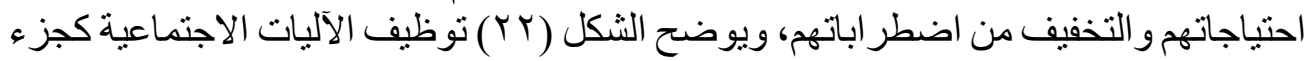

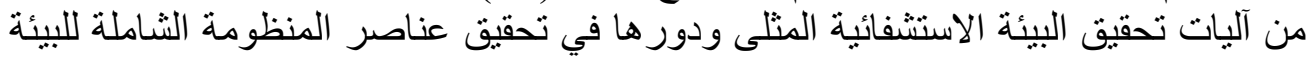

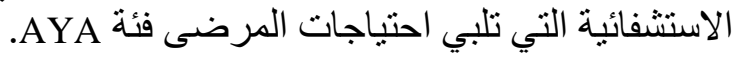

جدول (ء ا) ): مقارنة بين الثلاث نماذج ونسب تحقق الآليات الاجتماعية

\begin{tabular}{|c|c|c|c|c|c|c|c|c|c|}
\hline \multicolumn{3}{|c|}{ مفردة } & \multicolumn{3}{|c|}{ مزدوجة } & \multicolumn{3}{|c|}{ عنبر } & \multirow{2}{*}{ الآليات الاجتماعية } \\
\hline لا يتحقق & إلى حد ما & تحقق & لا يتحقق & إلى حد ما & تحقق & لا يتحقق & | إلى حل ما | ل & تحقق & \\
\hline$\%$ \% & $\% \curlyvee \wedge, \bullet$ & $\% \curlyvee \wedge, 0$ & $\% \circ \mathrm{V}$ & $\% \leqslant r$ & $\%$ & $\% 1 \ldots$ & $\%$ & $\%$ & الخصوصية و السيطرة \\
\hline$\% \Delta r$ & $\% r_{\bullet}, 0$ & $\% Y \square, 0$ & $\%$ \% & $\% r r, 0$ & $\% 11,0$ & $\% \wedge \bullet, 0$ & $\% 11,0$ & $\%$ & تحقيق سلامة المرضى \\
\hline$\%$ & $\% 1$ & $\%$ \% & $\% \curlyvee \wedge, 0$ & $\%$ ro & $\%$ & $\% 9 v$ & $\% \mu$ & $\%$ & تحسين النتائج الصحية للمرضى جودة الرعاية \\
\hline
\end{tabular}


$\Lambda \leq 0$

هاجر حدي، خالد الليثي، نوبي حسن، الآليات الاجتماعية ودورها في تحقيق البيئة الاستشفائية المثلى لغرف مرضى الأورام

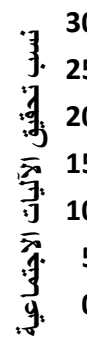

11.5

羿: 15

势 5
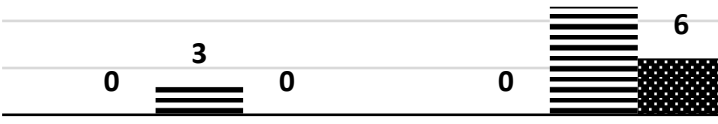

عنبر

مزدوجة

مفردة

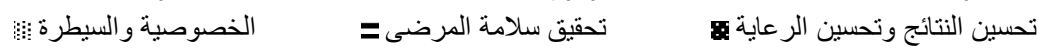

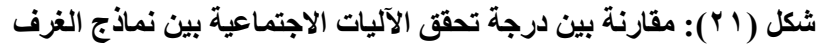

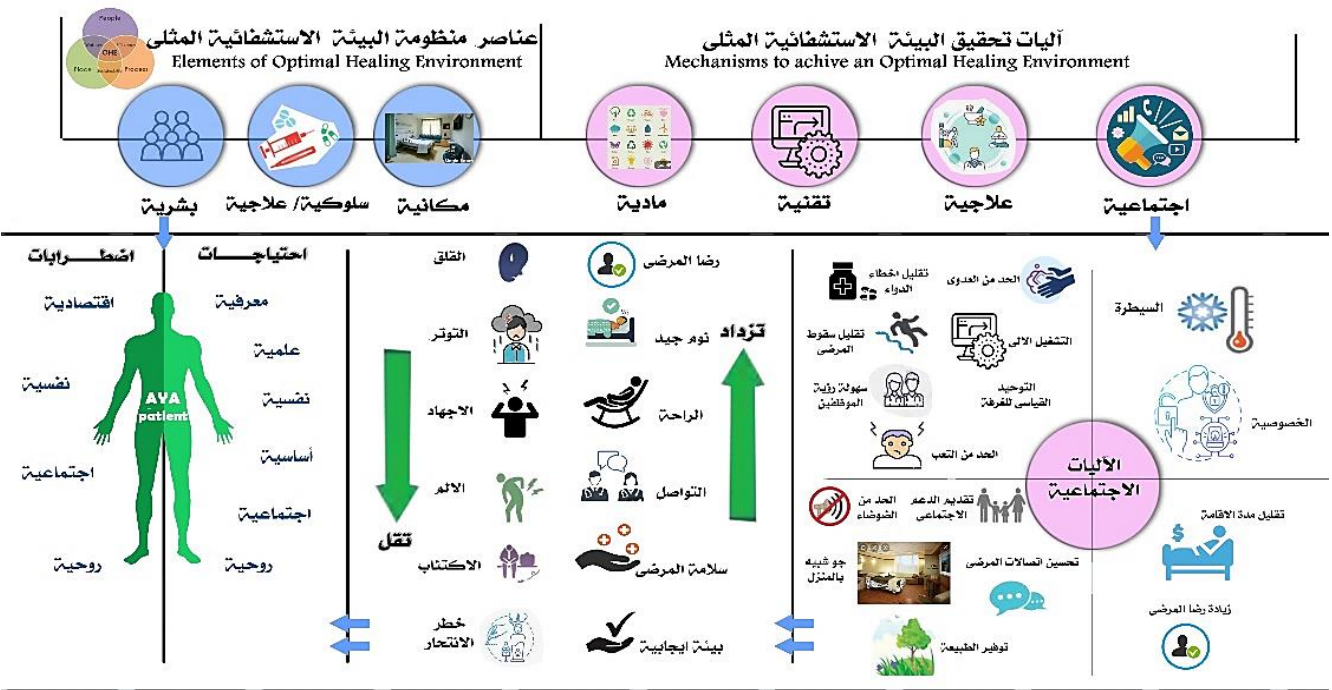

احنباجات ومنطاصبات مرضبر البشي الأورام

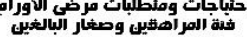

تحسيل الjتارح الصحبة

لوظيف الاليات الاجلماعية

شكل (r Y Y): الآليات الاجتماعية ودورها فى تحقيق احتياجات المرضى AYA

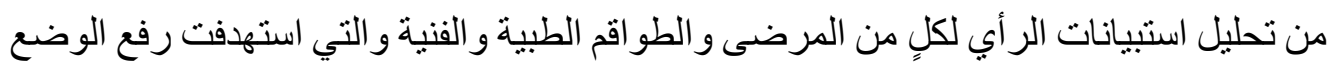

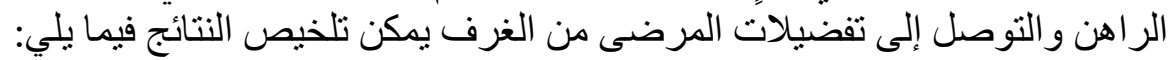

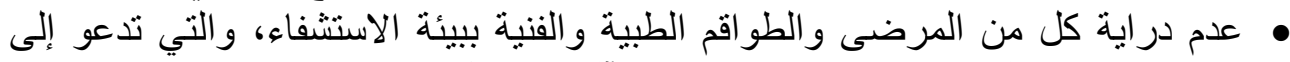

ضرورة توعية المستخدمين بييئة الاستشفاء و آليات وسبل ورئ تحقيقها.

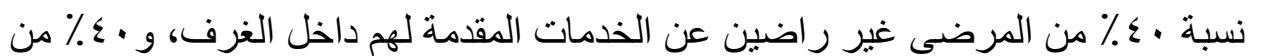

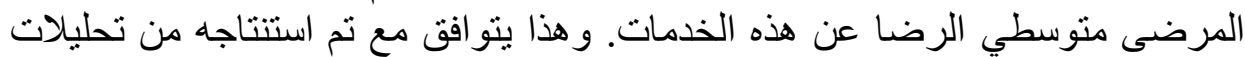
الغرف حيث تبين ضعف تحقيق الآليات في نماذج الغرف الثرفي الثناثة.

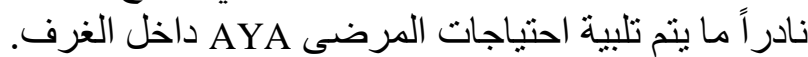

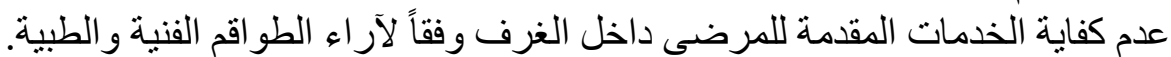

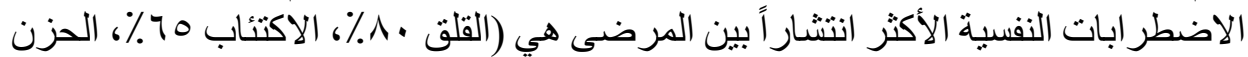

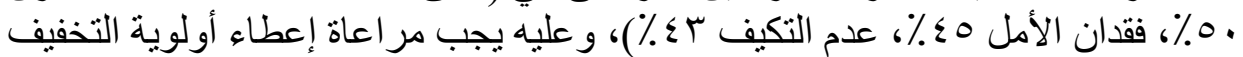

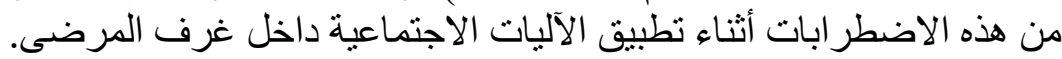
هفضل الطاقم الطبي و المرضى الغرف المفردة تلبها الغرف المزدوجة. 


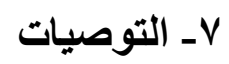

من نتائج التحليلات السابقة تبين وجود قصور في توظيف مفردات الآليات الاجتماعية داخل

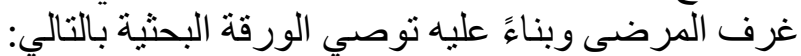

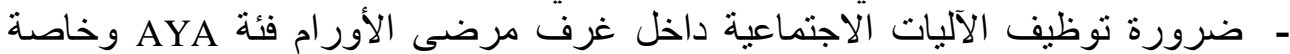

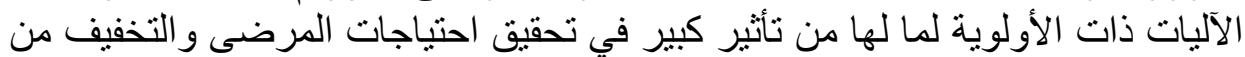

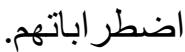
- استخدام الغرف المفردة كبيئة استشفائية ملائمة لفئة AYA لأنها الأكثر تحقيقاً للآليات

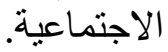

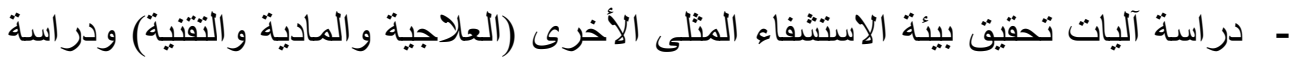

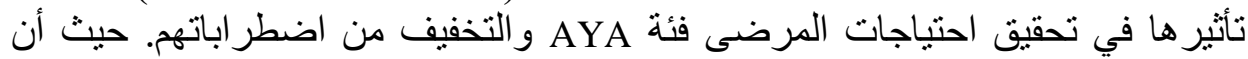

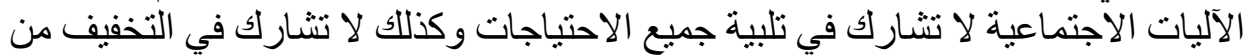

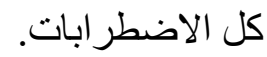

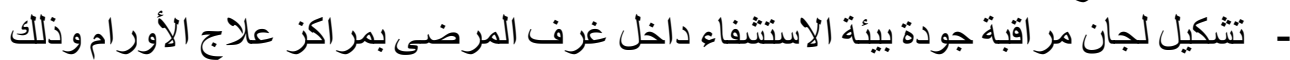
لضمان توظيف الآليات الاجتماعية بشكل سليم تحقيقاً لبيئة الاستشفاء المتلى الملائمة الألية

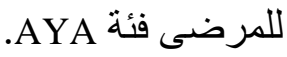

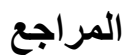

[1] Adler, Nancy E, and Ann EK Page, (2008) Cancer Care for The Whole Patient: Meeting Psychosocial Health Needs (National Academies Press).

[2] Alfonsi, E, S Capolongo, and M Buffoli, (2014) 'Evidence Based Design and Healthcare: An Unconventional Approach to Hospital Design', Ann Ig, 26: 13743.

[3] Arantzamendi, Maria, and Nora Kearney, (2004) 'The Psychological Needs of Patients Receiving Chemotherapy: An Exploration of Nurse Perceptions', European journal of cancer care, 13: 23-31.

[4] Baddarni, Kassim, (2010) 'Ethical Dilemmas and The Dying Muslim Patient', Asian Pac J Cancer Prev, 11: 107-12

[5] Bleyer, Archie W, and Ronald Duncan Barr, (2007) Cancer in Adolescents and Young Adults (Springer Science \& Business Media).

[6] Bloemberg, FC, A Juritsjeva, S Leenders, L Schltus, L Schwarzin, and L Wijnen, (2009) 'Healing Environments in Radiotherapy', Recommendations regarding healing environments for cancer patients. Project Report.

[7] Chaudhury, Habib, Atiya Mahmood, and Maria Valente, (2004) The Use of Single Patient Rooms Vs. Multiple Occupancy Rooms in Acute Care Environments (Simon Fraser University).

[8] Cullinan, By Kevin, and Martha Wolf, (2011)"The Patient Room: What is The Ideal Solution?" In Design Dilemma.

[9] D'Agostino, N. M., A. Penney, and B. Zebrack, (2004) 'Providing Developmentally Appropriate Psychosocial Care to Adolescent and Young Adult Cancer Survivors', Cancer, 117: 2329-34

[10] Dijkstra, Karin, (2009) Understanding Healing Environments: Effects of Physical Environmental Stimuli on Patients' Health and Well-being (University of Twente). 
هاجر حدي، خالد الليثي، نوبي حس، الأليات الاجتماعية ودورها في تحقيق البيئة الاستشفائية الدثلى لغرف مرضى الأورام

[11] Dossey, BM, (2013) 'Nursing: Integral, Integrative, and Holistic-Local to Global', Holistic nursing: A handbook for practice: 3-57.

[12] Firth, Kimberly, Katherine Smith, Bonnie R Sakallaris, Dawn M Bellanti, Cindy Crawford, and Kay C Avant, (2015) 'Healing, Aconcept Analysis', Global Advances in Health and Medicine, 4: 44-50.

[13] Gashoot, Moamer M., (2012) 'Healing Environment: A contribution to The Interior Design and Decor Features in Single Occupancy Hospital Rooms in Libya', Bournemouth University, School of Health and Social Care.

[14] Ghazali, Roslinda, and Mohamed Yusoff Abbas, (2017) 'Paediatric Wards: Healing Environment Assessment', Asian Journal of Environment-Behaviour Studies, 2: 83-93

[15] Gusella, Joanne L, Anne-Marie Ward, and Gordon S Butler, (1998). 'The Experience of Hospitalized Adolescents: How Well Do We Meet Thier Developmental Needs?', Children's Health Care, 27: 131-45

[16] Higby, Donald J., (2012) Supportive Care in Cancer Therapy (Springer Science \& Business Media).

[17] Jacobsen, P. B., and H. S. Jim, (2008) 'Psychosocial interventions for anxiety and depression in adult cancer patients: achievements and challenges', CA Cancer J Clin, 58: 214-30

[18] Linebaugh, Kelly Bartlett, (2013) A systematic Literature Review on Healing Environments in The Inpatient Health Care Setting (The University of Arizona).

[19] Miller, H., (2010). "Patient Rooms: A Changing Scene of Healing." In.: Healthcare.

[20] Oi-Zhen, Soh, Choong Weng-Wai, and Tan Yu-Tian, (2015) 'Quality of Healing Environment in Healthcare Facilities.'

[21] Paik, Jinkyung, (2014). 'An Integrated Review of Evidence-based Healthcare Design for Healing Environments: Focusing on Long-term Care Facilities.'

[22] Palmer, S., P. Patterson, and K. Thompson, (2014) 'A national Approach to Improving Adolescent and Young Adult (AYA) Oncology Psychosocial Care: The Development of AYA-Specific Psychosocial Assessment and Care Tools', Palliate Support Care, 12: 183-8.

[23] Lorenz, Susan G., (2007). 'The Potential of The Patient Room to Promote Healing and Well-Being in Patients and Nurses: An Integrative Review of The Research', Holistic nursing practice, 21: 263-77.

[24] Pfeiffer, Jane Bacon, (2014) Creating A Healing Environment: Strategies Christian Nurses Use (Loma Linda University

[25] Phillips, Tamara, (2012) Design of Acute Care Patient Rooms for Improved Patient/Family Experience: A Case for Interdisciplinary Collaboration (Carleton University).

[26] Priest ,Helena, (2010) 'Effective psychological Care for Physically Ill Patients in Hospital', Nursing Standard, 24: 48-56.

[27] Reiling, John, Ronda G Hughes, and Mike R Murphy, (2008) 'The Impact of Facility Design on Patient Safety.

[28] Sadatsafavi, Hessam, John Walewski, and Mardelle M Shepley, (2015)'Factors Influencing Evaluation of Patient Areas, Work Spaces, and Staff Areas by Healthcare Professionals', Indoor and Built Environment, 24: 439-56 
[29] Sakallaris, Bonnie R., (2012) Healing Relationships Skills and Attributes Survey: An Instrument Development Study (George Mason University).

[30] Shama, W., and S. Lucchetta, (2007) 'Psychosocial Issues of The Adolescent Cancer Patient and The Development of The Teenage Outreach Program (TOP)', J Psychosoc Oncol, 25: 99-112.

[31] Stichler, Jaynelle F., (2007) 'Is Your Hospital Hospitable?: How Physical Environment Influences Patient Safety', Nursing for women's health, 11: 506-11.

[32] Thomas, D. M., J. F. Seymour, T. O'Brien, S. M. Sawyer, and D. M. Ashley, (2006). 'Adolescent and Young Adult Cancer: A revolution in Evolution?', Intern Med J, 36: 302-7.

[33] Thomas, David M, Karen H Albritton, and Andrea Ferrari, (2010) 'Adolescent and Young Adult Oncology: An Emerging Field', Journal of Clinical Oncology, 28: 4781-82.

[34] Wein, Simon, Shlomit Pery, and Alona Zer, (2010) 'Role of Palliative Care in Adolescent and Young Adult Oncology', Journal of Clinical Oncology, 28: 4819-24.

[35] Weis, J. 2003. 'Support Groups for Cancer Patients', Support Care Cancer, 11: 763-8 .

[36] Yoo, In-Young, (2015) 'A Study on Healing Environmental Factors in The Elderly Patients with Long-Term Care', International Journal of Bio-Science and Bio-Technology, 7: 267-76.

[37] Zebrack, B., and S. Isaacson, (2012). 'Psychosocial Care of Adolescent and Young Adult Patients with Cancer and Survivors', J Clin Oncol, 30: 1221-6.

[38] Zebrack, B., and S. Isaacson, (2012)'Psychosocial Care of Adolescent and

Young Adult Patients with Cancer and Survivors', J Clin Oncol, 30: 1221-6.

[39] Zimring, Craig, Anjali Joseph, and Ruchi Choudhary, (2004) 'The Role of The

Physical Environment in The Hospital of the 21st Century: A once-in-aLifetime Opportunity', Concord, CA: The Center for Health Design.

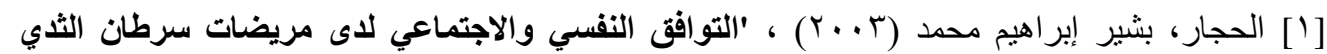

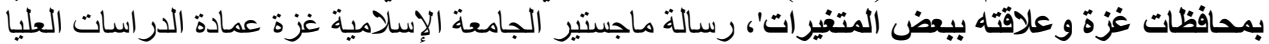
كلية التربية قسم علم النفس.

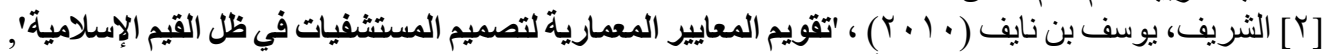

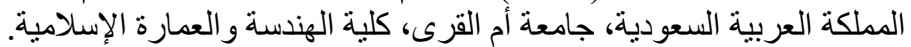

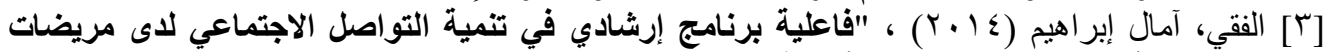

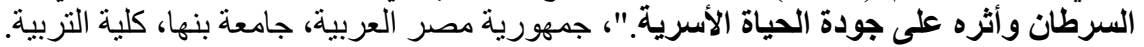

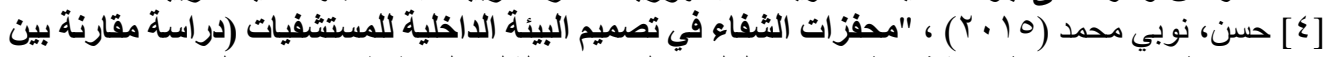

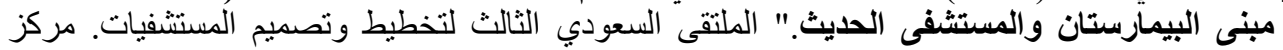

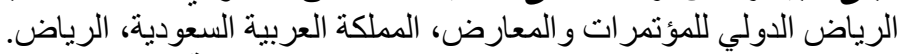

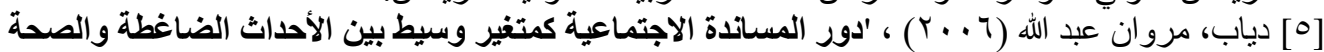

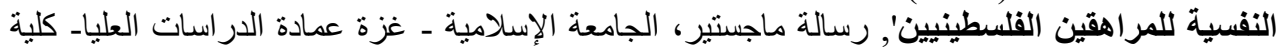

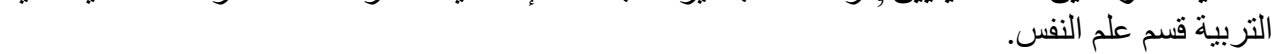

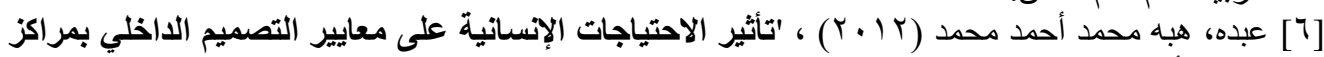

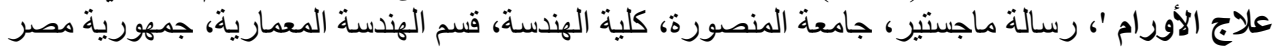
العربية. - ل الاون

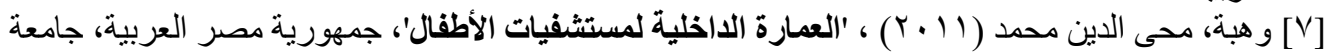
حلوان، كلية الفنون الجميلة، قسم الديكور، شعبة العمارة الداخلية. 
$\Lambda \leq q$

هاجر حدي، خالد اللثيي، نوبي حسن، الآليات الاجتماعية ودورها في تحقيق البيئة الاستشفائية الدثلى لغرف مرضى الأورام

\title{
The Role of Social Mechanisms in Achieving the Optimal Healing Environment for Oncology Patients Rooms (Adolescents and Young Adults Category-AYA)
}

\author{
Hager Hamdy Mohamed ${ }^{1}$, Khaled Mohamed Ahmed El-Lithy ${ }^{1}$, Nouby Mohamed Hassan ${ }^{1}$ \\ 1. Department of Architecture, Faculty of Engineering, Assiut University
}

\begin{abstract}
This paper discusses the importance of social mechanisms as one of key elements for achieving optimal healing environment-OHE for oncology patients' rooms, by overviewing the current status of some oncology centers, which focus solely on providing medical treatment without taking into account social, psychological, emotional and spiritual needs of patients, which in turn negatively affect the treatment and recovery of patients, especially adolescents and young adults-AYA, where the challenges of emotional and social resulting from cancer with challenges resulting from adolescence and adulthood.

This paper aims to extract social mechanisms for oncology patient rooms, and indicate their role and priorities which will be applied with matching needs of patients of AYA category, mitigating their disorders, and impacts on patients' health outcomes.

This paper attempts to reach the best appropriate model to achieve these mechanisms, by analyzing the current situation of selected samples from case study of the South Egypt Cancer Institute in Asyut. Through this analysis, this paper presents a set of results and recommendations that should be followed to develop patient rooms, which take into account the provision of social mechanisms and the implementing priorities depending on impact level of each element in order to reach the suitable setting for the optimal healing environment of the room.

This paper relies the analytical descriptive approach to deal with the research problem by revising literature that dealt with the characterization and analyzing the needs of AYA oncologists in patient rooms, identifying the disorders and effects of the disease on this category, then identifying the appropriate social mechanisms that can be match their needs in the rooms. An analytical and deductive approach is followed through implementing various research tools and procedures to analyze the coverage of current status to know how these mechanisms are achieved within different models of patient rooms and how they affect patient health, then to analyze data and outcomes results.

Finally, this paper concludes with a comprehensive chart of social mechanisms' matrix suitable for optimal healing environment in AYA patients' rooms.
\end{abstract}

Keywords: Optimal Healing Environment, Social Mechanisms, Patient Rooms, Oncology patients' needs, Adolescents and Young Adults. 